\title{
Interfaces, syntactic movement, and neural activation: A new perspective on the implementation of language in the brain
}

\author{
Ken Ramshøj Christensen ${ }^{\mathrm{a}, \mathrm{b}, *}$ \\ ${ }^{a}$ Center for Functionally Integrative Neuroscience (CFIN), Aarhus University Hospital, Denmark \\ ${ }^{\mathrm{b}}$ Institute for Language, Literature, and Culture, University of Aarhus, Denmark
}

Received 1 March 2006; received in revised form 7 January 2007; accepted 10 January 2007

\begin{abstract}
Studies of language deficits as well as neuroimaging studies indicate that syntactic processing of displaced constituents is implemented in the brain as a distributed cortical network of modules. The data from the present fMRI study on two types of syntactic movement in Danish offers further support for such a distributed syntactic network. These results, together with the results from a number of other fMRI studies in the literature, form the basis for the Domain Hypothesis according to which differential activation in the subcomponents of the cortical network reflects computation of different syntactic domains - the interface levels between syntax, semantics, and pragmatics. The activation patters result from the interaction between movement and target domain, not (non-) canonicity or working memory per se. Specifically, movement to the CP-domain activates areas including Broca's area and the temporal-occipital-parietal junction, whereas movement to the IPdomain does not, but activates the left anterior temporal cortex.
\end{abstract}

(C) 2007 Elsevier Ltd. All rights reserved.

Keywords: Language; Interfaces; Syntax; Movement; Broca's area; Temporal cortex

\footnotetext{
*Institute for Language, Literature, and Culture, University of Aarhus, Jens Chr. Skous Vej 5, DK-8000 Aarhus C, Denmark.

E-mail address: engkrc@hum.au.dk.
} 


\section{Introduction}

A central idea to formal linguistic theory is that the structure building system, the syntax, mediates between sound and meaning and in doing so, interfaces with other cognitive systems. In this paper, I shall argue that these interfaces also have cortical correlates, and that syntactic processing involves far more areas of the brain than is often assumed.

This network will form the basis for a hypothesis about the interfacing between syntax and other cognitive systems, stating that syntactic movement operations will increase neural activation depending on which syntactic domain is targeted.

In cognitive neuroscience, however, the widespread notion applied to syntax and wordorder changes is working memory (WM). I shall argue that the results of a number of studies on neurosyntax as well as some apparent exceptions to a general correlation between Broca's area and changes in word order are better accounted for within a formal linguistic framework.

\subsection{Interfacing: structure-to-meaning mapping}

Syntax, the computational system of human language $\left(C_{\mathrm{HL}}\right)$, derives a set of symbolic representations, Phonetic Form (PF) and Logical Form (LF), sound and meaning, respectively, from a lexical array taken from the mental lexicon. The derivation consists of recursive cyclic Merge (basic structure composition) and Move (displacement). PF and LF are interface levels, linguistic representations that are sent to the performance systems, the Articulatory-Perceptual and Conceptual-Intentional systems.

Various linguists have proposed that the mapping from syntax to meaning proceeds stepwise, that is, semantic composition at LF is incremental. For example, there are multiple interfaces (Platzack, 2001a), multiple spell outs (Uriagereka, 1999) or phases (Chomsky, 2001, 2004, 2005, in press); the syntactic tree maps onto a presupposition-focus structure (the Mapping Hypothesis, Diesing, 1997), and the three domains have articulated structure (e.g. left periphery phenomena, Rizzi, 1997).

I shall focus on the derivation from lexical array to LF (from a set of words to the meaning of a clause). As illustrated in Fig. 1, at various points during the derivation,

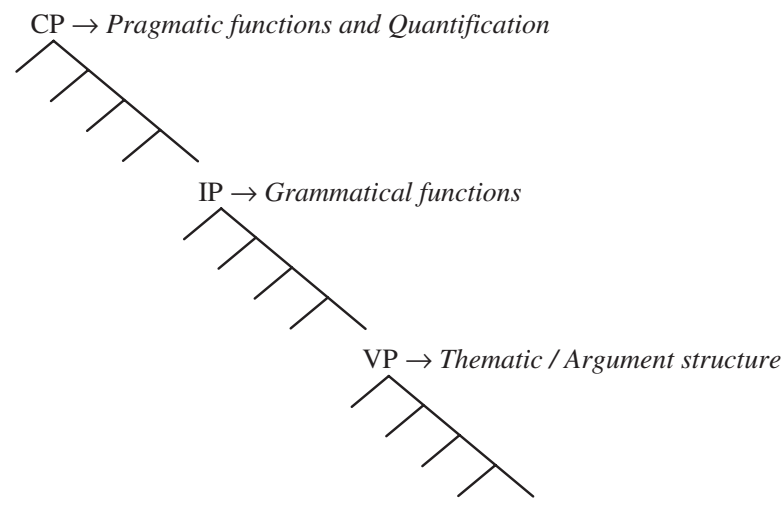

Fig. 1. Structure-to-meaning mapping. 
namely at VP, IP, and CP, the computational system interfaces with higher cognitive systems. According to Platzack (2001a), VP maps into Thematic Form (argument structure, the "who did what to whom?"), IP into Grammatical Form (tense, aspect, voice, polarity, and the subject-predicate relation, variously known as the Nexus or the Extended Projection Principle, EPP), and CP into Pragmatic Form (Illocutionary Force, Topic, Focus). Similarly, Hinzen (2006, p. 215) argues that VP is the Thematic layer, IP the Agreement layer, and CP the Quantificational layer. The exact natures of the semantic layers the syntactic domains map into are not crucial here. What is important is that they are different.

The syntactic derivation or computation is (i) defined by the kinds of operations it consists of, namely successive cyclic and recursive Merge and Move, (ii) subject to constraints on computational economy (e.g. phases, locality, last resort, and symmetry breaking) and structure dependency (e.g. constituency, phrase structure, c-command, the extension condition, and shape conservation) (cf. e.g. Saddy \& Uriagereka, 2004, p. 388; Chomsky, 1995, pp. 318-319), and (iii) may (sometimes) be motivated by interfacing/ mapping with e.g. information structure (but see Hinzen, 2006, pp. 208-220). Sometimes movement may be either triggered or blocked by something other than meaning in a broad sense, for example language-specific (parameterized) differences in head-complement order, affixation/cliticization, and EPP checking.

As argued by Marantz (2005, p. 400), "the categories and operations of generative grammar are hypotheses about the representations and computations in the minds and brains of speakers". Focussing on the three syntactic domains, VP, IP, and $\mathrm{CP}$, and their mappings, the question is then how they are implemented. "If a linguistic analysis is correct-i.e. identifies something real-it identifies computations/ representations that are computed in the minds/brains of speakers. How these computations are implemented at different levels of biological abstraction is the primary analytical question for neurolinguistics" (Poeppel \& Embick, 2004, p. 12). In what follows I shall argue that differential neural activation in syntactic processing reflects the computations associated with syntactic movement to specific syntactic domains and interfacing between these domains and higher cognitive systems (the ConceptualIntentional interface, CI). That is, there is a movement $\times$ target domain interaction effect

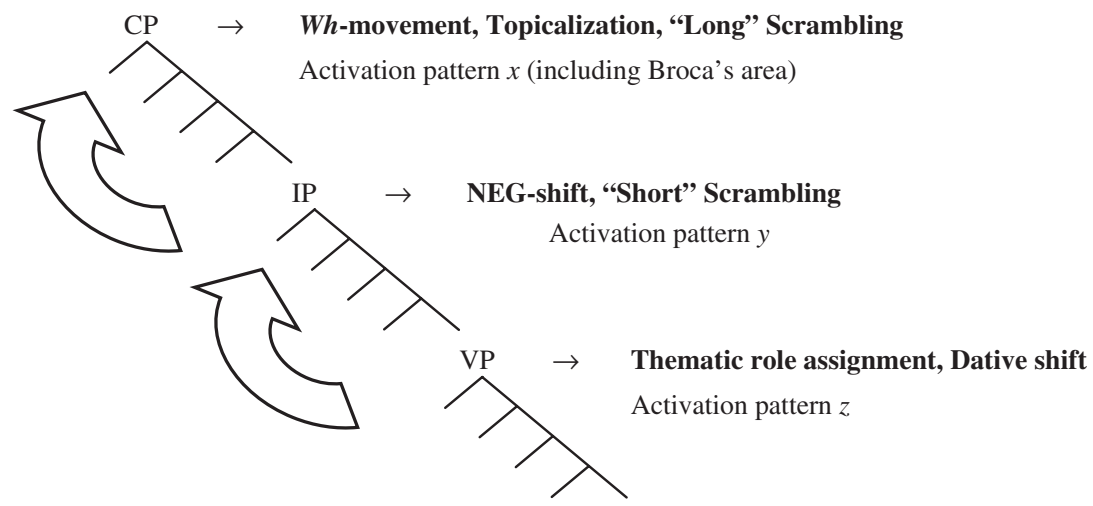

Fig. 2. Movement and activation. 
(see also Fig. 2):

The Domain Hypothesis:

The effect of syntactic movement in terms of neural activation is dependent on the target domain of the movement in question.

The primary concern of this paper, however, is the different effects of movement to IP and CP. The IP-domain has so far been rather overlooked in neurolinguistic studies. The problem is that it is generally difficult to find XP (phrasal) movement that does not have consequences for semantic interpretation; that is, does not change the order of the theta-roles or affect the "who did what to whom". For example, it makes a lot of difference which argument raises to subject or which constituent is topicalized or focalized. Notable exceptions are adjunct scrambling and NEG-shift, and the latter is the focus of the present fMRI study.

The present model combines three findings: (i) that left-hemisphere damage leads to specific syntactic impairments (agrammatism) which affects some syntactic movement, namely those that target the CP-domain; (ii) that right-hemisphere damage leads to impairments that affects the assignment of thematic roles to arguments and integrating them into event structure, which is internal to the VP-domain; and (iii) that these two target domains, I shall argue, have different neural activation patterns in fMRI studies on normal subjects.

Research has shown that the brain functions by constantly 'predicting' or 'anticipating' incoming information, as for example in language (see below) and music (Culicover, 2005; Maess, Koelsch, Gunter, \& Friederici, 2001; Vuust et al., 2005). This principle of prediction is known in cognitive science as, e.g., Predictive Coding (Friston, 2003) and Anticipatory/Preparatory Set (Fuster, 2003), and in psycholinguistics as Top-Down Parsing (going back to Kimball, 1973) and Syntactic Prediction (Gibson, 1998). In generative syntax this principle is also required both for Merge, in the form of Selection/ Subcategorization, and for Move with the antecedent, the moved element, c-commanding (basically, sitting higher in the tree than) its trace or traces.

In the generative syntactic model outlined above, interpretation is cyclic. The linguistic system does not wait until the completion of the derivation before beginning interpretation. The same goes for processing, where comprehension is not suspended until the whole string has been parsed. That does not mean, however, that structure is built top-down by a top-down parser.

Neurophysiological studies of the microvolts of the brain using event-related brain potentials (ERP) have shown that syntactic structure building, the derivation, is very fast. For example, the determiner the selects a noun phrase such as brown dog and when merged they form the determiner phrase (DP) the brown dog. If instead, the is followed by an auxiliary verb, such as could, the selectional restrictions of the has been violated. Such phrase structure violations are associated with a negativity effect in the left frontal lobe after approximately $120-220 \mathrm{~ms}$ after the violation, a so-called Early Left Anterior Negativity (ELAN). Furthermore, the P600, a centro-parietal positivity after $600-900 \mathrm{~ms}$ is evoked by structural reanalysis (between the two, the bilateral centro-parietal negative N400 occurring after approximately $400 \mathrm{~ms}$ reflects the cost of semantic or thematic integration). (See Friederici, 2002, Osterhout and Nicol, 1999, and Saddy and Uriagereka, 2004 for overviews.)

In comprehension, competing structures (derivations) compatible with the lexical input, and hence cortical networks involved in the computation of the relevant subcomponents of 
the interpretation, are activated in parallel, although the favored or most plausible one is activated the most. In a sense, then, the top-down parser is incrementally selecting (by activation) among competing 'ready-made' structures that are rapidly derived bottom-up. Thus, Merge and Move have already taken place in the structures the parser operates on. Because the basic clause structure, the 'clausal spine', CP-IP-VP, is universal, as soon as the parser identifies a $\mathrm{CP}$ (an element filling either spec-CP, or the head of $\mathrm{CP}, \mathrm{C}^{\circ}$ ), it immediately predicts a full clause structure to follow.

Consider the following example of the parsing of (2):

Øllen har Peter købt.

Beer-the has Peter bought.

'The beer, Peter bought.'

Øllen 'the beer' is initially only a DP. When the parser is presented with the second word, har 'has', the system predicts a full clause because in Danish main clauses, the finite verb occupies $\mathrm{C}^{\circ}$, and $\mathrm{C}^{\circ}$ selects an IP (in the derivation $\mathrm{C}^{\circ}$ is merged with IP). This IP is headed by a finite $\mathrm{I}^{\circ}$ marked for present tense and contains a trace of har. In turn $\mathrm{I}^{\circ}$ selects a VP. This VP is headed by the trace of the moved auxiliary verb har which selects another VP headed by the main verb. See Fig. 3(a) (predicted structure is grayed).

So far, ollen cannot be assigned a thematic role (or $\theta$-role) because the main verb is not yet parsed. However, the parser 'knows' that it occupies spec-CP (because it precedes har in $\mathrm{C}^{\circ}$ ) and that it may be the topic and/or the subject of the clause. This knowledge about subject- or topichood comes from the interfacing between syntax and CI. The bare structure of $\mathrm{CP}$ itself conforms to X-bar structure, as does any phrase, as generated by the computational system. The function of spec-CP, on the other hand, is determined by, for example, pragmatic functions.

When the parser encounters Peter, Fig. 3(b), it assigns it the grammatical role of subject, because it fills spec-IP. The 'function' of the IP-domain, or rather, the interpretation it is given at the interface between syntax and CI, is (among other things, see above) to determine the subject-predicate (or Nexus) relation. Given that Peter is the subject, øllen is not, only the topic. Again, because the main verb is not yet parsed, thematic roles cannot be assigned.

Finally, the verb købt 'bought' is parsed as the main verb heading the lower VP. From the meaning of købt two semantic roles are predicted: an Agent (the buyer), assigned to Peter because being an Agent requires animacy, and a Theme (the thing bought), assigned to ollen. Thus, the system predicts two positions in VP where these roles are assigned, namely spec-VP, the base-position of Peter, the Agent, and the complement of $\mathrm{V}^{\circ}$, the object position, the base-position of øllen (see (c) in Fig. 3).

Note that for each instance of prediction of base-positions and positions filled by traces, something else is also required, namely, working memory. In the present example, ollen is kept in WM until it is assigned a thematic role (Theme) in its base-position inside VP where it is selected by and merged with the verb. So, there is both 'look ahead' and 'look back'.

\subsection{The distributed syntax network}

Broca's and Wernicke's areas, the 'classical' language areas, are often assumed to be the locus of syntax and semantics, respectively. However, a brief look at the neurolinguistics 


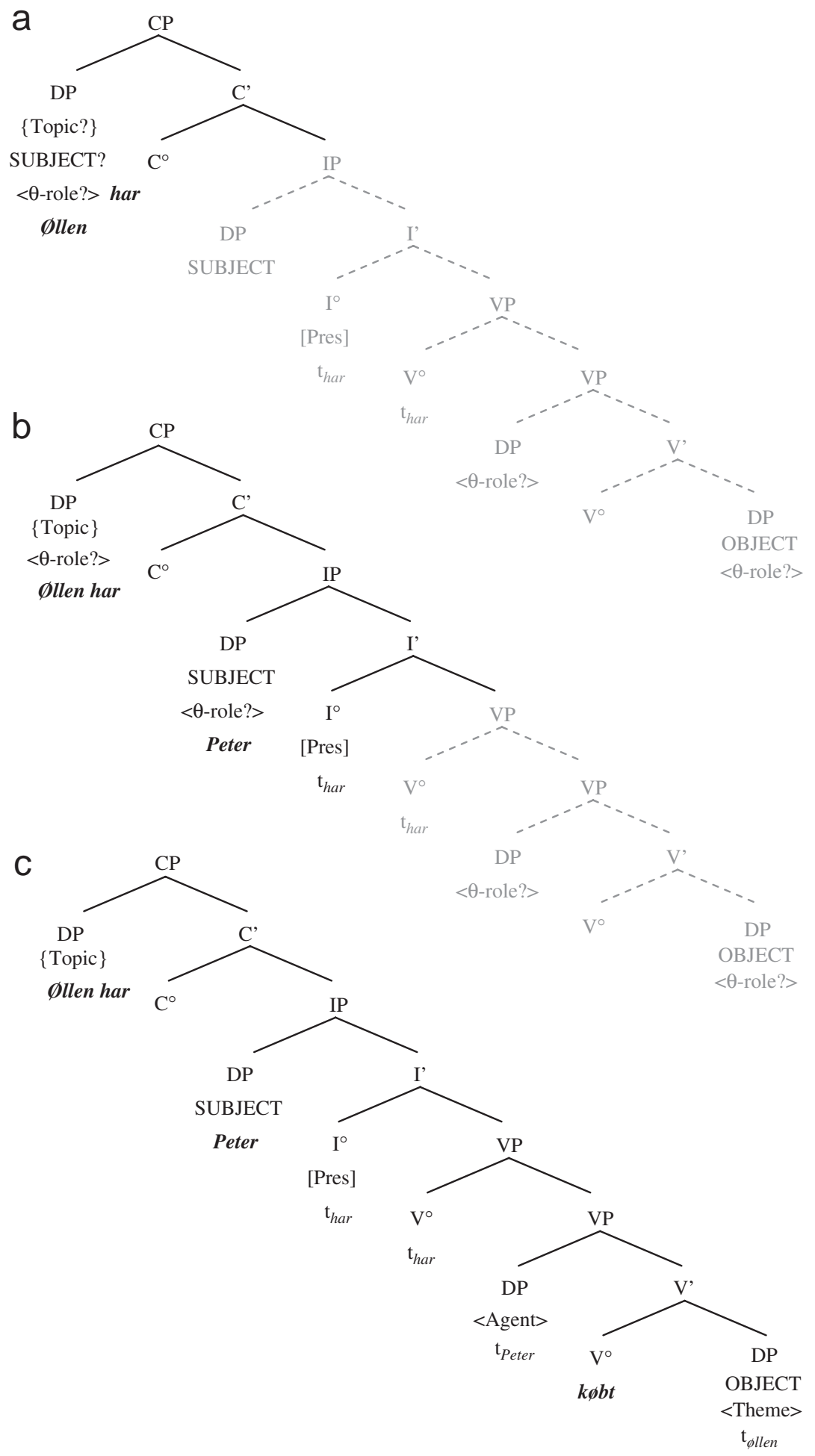

Fig. 3. Top-down parsing. 
literature shows that things are far more complicated. Focussing on studies of syntax and the brain, neural activation is found in a number of areas even outside the classical language areas. For example, Dogil et al. (2002) asked subjects to perform two reserialization tasks. In the first task, a structure-dependent task, the subjects had to reformulate subject-initial sentences such that they started with a different constituent than the subject; in other words, a topicalization task. The other task was a list re-serialization task where the subjects were asked to reorder a list of words such that the second word was moved to the first position, e.g. ABC $\rightarrow$ BAC. When subtracting the re-serialization task from the topicalization task, Dogil et al. (2002, p. 82) found activation in "in the left dorsolateral frontal lobe, extending to Broca's area, and at the level of left temporal lobe, encroaching on Wernicke's area [...] anterior cingulate gyrus [...] and the cerebellum" as well as in the dorsal prefrontal cortex. They conclude that "the structure-dependency of syntactic operations is controlled by a delineated network" (p. 83). (This subtraction is actually not a subtraction of two minimally different conditions; it is not sufficiently constrained and the result may reflect more than structure-dependency). Notably, this network is not necessarily specific to syntax or even to language. "The coactivated cerebral-cerebellar network has been claimed to function as a WM for time sensitive operations. [...] It is remarkable, however, that networks and structures usually connected with WM are coactivated by a syntax-specific task. The dorsal prefrontal cortex (DPF) is exactly one such area that has always been associated with memory and almost never with language" (Dogil et al., 2002, p. 84). The recruitment of the cerebellum may, however, have to do with automation rather than time sensitivity (though clearly these two factors are inter-dependent). Automated processes include learnt and acquired as well as innate skills and reflexes that are processed below the level of consciousness (cognition and intention). "Roles of the cerebellum in cognitive functions are suggested by deficits induced by cerebellar lesions in cognitive planning, in practice-related learning and error detection, in judging time intervals, in rapidly shifting attention between sensory modalities, and in cognitive operations in three-dimensional space [...]" (Ito, 2000, pp. 159-160). Take for example the difference between wilfully reaching out for a glass and the complex coordination of the muscles in the arm and hand controlling the elbow, hand and fingers, or the difference between, say, playing piano scales as an amateur and the effortlessness and rapidity associated with mastery. (Here and in the analysis below, I shall treat the cerebellum as an undifferentiated organ/module which, of course, is a gross simplification). The crucial point, however, is this: "The syntax network [...] is widely distributed in the human brain. The focal areas of the network (Broca's area, Wernicke's area, cerebellum, [dorsal prefrontal], [anterior cingulate cortex]) are very strongly interconnected" (Dogil et al., 2002, p. 85).

There is also evidence that the network includes the anterior portion of the superior temporal cortex. In fact, Humphries, Love, Swinney, and Hickok (2005, p. 129) report that "[anterior temporal cortex] is one part of a larger, distributed sentence-processing network". It shows greater activation for sentences than for word lists, regardless of modality (visual or auditory) and intonation/prosody (normal sentence, list, or flat intonation), and it is activated more by syntactically well-formed sentences than by illformed sentences (formed by randomly selected words, not by random permutations) with normal sentence intonation. They conclude that a part of the anterior temporal cortex "responds preferentially to structured sentence stimuli, and that this response preference cannot be attributed to acoustic-phonetic, lexical-semantic, or prosodic factors" 
(Humphries et al., 2005, p. 135). This preference, they suggest, may be driven by the integration of syntactic and combinatorial semantic computations.

Thus, while linguistic processing (in a broad sense) may recruit a range of cortical areas across the whole brain, syntactic processing is implemented as a distributed network of computational centers. In other words, "abstract function is localized in focal areas" (Dogil et al., 2002, p. 86). When tasks are made increasingly more fine grained (taking into account fine syntactic distinctions), only a subsection of the whole large-scale linguistically recruited network will show up in subtraction results, and what we see is a vanishing network: In lexically and syntactically more constrained tasks, the areas activated "will probably be a part of the large-scale [speech] network that we discovered, but the network itself will become "invisible"' (Dogil et al., 2002, p. 87).

The main focal areas of the distributed syntax network are the left frontal gyrus (LIFG) including Broca's area and its vicinity, the left posterior superior temporal gyrus (LpSTG) including Wernicke's area and its vicinity (the Temporal-Occipital-Parietal Junction), left anterior temporal superior gyrus (LaSTG) and their right-hemisphere homologues, as well as the dorsal prefrontal cortex, the cerebellum, and the anterior cingulate gyrus (on the inter-hemispheric surface). The network is compatible with the results from a wide range of other neuroimaging studies, e.g. Ben-Shachar, Hendler, Kahn, Ben-Bashat, \& Grodzinsky (2003), Ben-Shachar, Palti, \& Grodzinsky (2004), Cooke et al. (2001), Dapretto and Bookheimer (1999), Embick, Marantz, Miyashita, O’Neil, and Sakai (2000), Fiebach, Schlesewsky, Lohmann, von Cramon, and Friederici (2005), Grewe et al. (2005), Humphries et al. (2005), Just, Carpenter, Keller, Eddy, and Thulborn (1996), Newman, Just, Keller, Roth, and Carpenter (2003), Röder, Stock, Neville, Bien, and Rösler (2002), and Wartenburger et al. (2004).

In the next Section I review six syntactic neuroimaging studies. In three of these studies, I propose an alternative syntactic analysis of the linguistic stimuli making both stimuli and imaging results compatible with the Domain Hypothesis. Importantly, this also shows that results from experiments based on different linguistic frameworks can be made compatible as long as both results and linguistic input (and, optimally, also the specific analysis of the data underlying the test hypotheses) are included in the published material.

\subsection{Neuroimaging studies}

Ben-Shachar et al. (2003) present an fMRI experiment on relative clauses in Hebrew. When contrasting object relatives, (3)a, with embedded declaratives, (3)b, they found that object relatives increased activation in Broca's area (BA44/45), but also bilaterally in the posterior superior temporal gyrus (BA22/39), i.e. Wernicke's area and its right hemisphere homologue. (The results of the imaging studies discussed in this section as well as the results discussed above from Dogil et al. (2002) are summarized in Table 1.)

$$
\begin{array}{ll}
\text { a. (I helped the girl) [CP OP that [IP Mary saw } t \text { in the park]] } \\
\text { b. (I told Mary) } & \text { [CP that [IP the girl ran in the park]] }
\end{array}
$$

As all other parameters are kept constant, it is safe to assume that the observed activation is due to the movement of the object to spec-CP. "The neural activity evoked by 
Table 1

Summary of other fMRI studies

\begin{tabular}{|c|c|c|c|c|c|c|c|}
\hline \multirow{2}{*}{$\begin{array}{l}\text { Target } \\
\text { domain }\end{array}$} & \multirow[t]{2}{*}{ Movement contrast } & \multicolumn{6}{|c|}{ Activation clusters } \\
\hline & & IFG/ant. ins & VPrCG (BA6) & $\begin{array}{l}\text { Heschl's } \\
\text { (BA41/42) }\end{array}$ & pSTG & $\begin{array}{l}\text { Dorsal PrFG } \\
\text { (BA6/8) }\end{array}$ & $\begin{array}{l}\text { Ant. cing. } \\
\text { (BA24/32) }\end{array}$ \\
\hline \multirow[t]{8}{*}{$\mathrm{CP}$} & $\begin{array}{l}\text { Obj. rel>emb. decl. } \\
\text { (Ben-Shachar et al., 2003) }\end{array}$ & $\mathrm{L}$ & - & - & $\mathrm{L}+\mathrm{R}$ & - & 一 \\
\hline & $\begin{array}{l}\text { Wh }>\text { yes/no } \\
\text { (Ben-Shachar et al., 2004) }\end{array}$ & $\mathrm{L}$ & $\mathrm{L}$ & - & $\mathrm{L}+\mathrm{R}$ & - & - \\
\hline & $\begin{array}{l}\text { Topic > subj. Initial } \\
\text { (Ben-Shachar et al., 2004) }\end{array}$ & $\mathrm{L}$ & $\mathrm{L}$ & $\mathrm{L}$ & $\mathrm{L}+\mathrm{R}$ & - & - \\
\hline & $\begin{array}{l}\text { Topic }>\text { re-serial. } \\
\text { (Dogil et al., 2002) }\end{array}$ & $\mathrm{L}$ & $\mathrm{L}$ & - & $\mathrm{L}$ & $X$ & $\mathrm{X}$ \\
\hline & $\begin{array}{l}\text { "Long"> "short subj." (scrambling } \\
\text { above subj.) } \\
\text { (Fiebach et al., 2005) }\end{array}$ & $\mathrm{L}+\mathrm{R}$ & - & - & $\mathrm{L}+\mathrm{R}$ & - & - \\
\hline & $\begin{array}{l}\text { Subj-IO > IO-Subj (scrambling above } \\
\text { subj.) } \\
\text { (Grewe et al., 2005) }\end{array}$ & $\mathrm{L}+\mathrm{R}$ & - & - & - & - & - \\
\hline & $\begin{array}{l}\text { Double obj. scrambling } \\
\text { (Grewe et al., 2005) }\end{array}$ & $\mathrm{L}$ & - & - & - & - & - \\
\hline & $\begin{array}{l}\text { "Easy" > "difficult" (scrambling above } \\
\text { subj.) } \\
\text { (Röder et al., 2002) }\end{array}$ & $\mathrm{L}+\mathrm{R}$ & $\mathrm{L}$ & - & $\mathrm{L}$ & - & $\mathrm{X}$ \\
\hline \multirow[t]{2}{*}{ IP } & $\begin{array}{l}\text { "Long"> "short obj." (scrambling } \\
\text { below subj.) } \\
\text { (Fiebach et al., 2005) }\end{array}$ & - & - & - & - & - & - \\
\hline & $\begin{array}{l}\text { Pronominal scrambling } \\
\text { (Grewe et al., 2005) }\end{array}$ & - & - & - & - & - & - \\
\hline \multirow[t]{2}{*}{ VP } & $\begin{array}{l}\text { Dative shift } \\
\text { (Ben-Shachar et al., 2004) }\end{array}$ & $\mathrm{R}$ & $\mathrm{R}$ & - & - & - & - \\
\hline & $\begin{array}{l}\text { "Semantic"> "nonsemantic" } \\
\text { (Röder et al., 2002) }\end{array}$ & $\mathrm{R}$ & - & - & - & - & - \\
\hline
\end{tabular}


transformational analysis sets this process apart from other putative sources of computational complexity during sentence perception" (Ben-Shachar et al., 2003, p. 439).

Ben-Shachar et al. (2004) found that topicalization (in Hebrew) increased activation in Broca's area (BA44/45), left ventral precentral gyrus (L-vPrCG, BA6 bordering on BA9), and bilaterally in BA39 bordering on BA22/37 in the posterior superior temporal gyrus (pSTG), that is, in Wernicke's region, as well as in the primary auditory cortex, Heschl's complex (BA41/42).

When presenting their subjects with embedded wh-questions and yes/no questions, BenShachar et al. (2004) found that wh-movement increased activation in left inferior frontal gyrus (LIFG) and, as with topicalization, L-vPrCG and bilateral pSTG. They did not find any significant difference between subject and object wh-questions which, at first sight, is surprising. However, both conditions crucially involve movement to spec-CP and according to the Domain Hypothesis in (1) no differential activation is predicted in Broca's area.

So far, the contrasts have involved movement to the CP-domain and have all shown activation in Broca's area. Ben-Shachar et al. (2004) also tested the so-called dative alternation or dative shift, illustrated in (4):
a. John gave
[the red book] to [the professor from Oxford]
b. John gave [the professor from Oxford] [the red book] to $t$

Theoretically, this alternation is VP-internal as it does not involve movement to the higher domains (whether this difference is due to movement or base-order is a separate issue). The contrast did not increase activation in Broca's area. However, activation was found in the right ventral precentral gyrus (R-vPrCG) and right anterior insula (R-aINS). This is a pattern very different from the movements to the CP-domain.

Röder et al. (2002) investigated word order differences in German derived by the movement operation known as scrambling. The test sentences were different permutations of strings of words as exemplified in the partial representations in (5) (based on Röder et al., 2002, p. 1005; the structural analysis is mine; the authors do not provide one. $\mathrm{IO}=$ indirect object, $\mathrm{DO}=$ direct object). (I leave aside details about the base-positions and movements of the finite auxiliary will and the adverbial jeztz as both are kept constant in all examples; in the structures, will is in $\mathrm{C}^{\circ}$, and jetzt is in spec-CP). As a control they used nonword ("nonsemantic") sentences corresponding to the well-formed ("semantic") ones.
a. [CP Adv Aux
[IP Subj [vP
IO DO Verb]]]
("Easy"/ short)
b. [CP Adv Aux
[IP Subj [vP

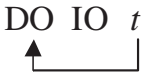
Verb]]] ("Easy" / short)
c. [CP Adv Aux

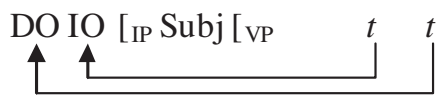
Verb]]]
("Difficult" / long)
d. [cP Adv Aux

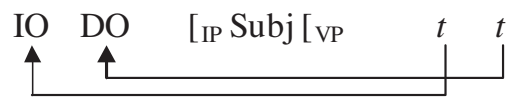
Verb]]] ("Difficult" / long) 
When they contrasted the sentences where both the indirect object (IO) and the direct object (DO) follow the subject (the "easy" examples) with those where IO and DO precede the subject ("difficult"), they found increased activation in LIFG (BA44/45), left middle and superior temporal gyrus pSTG (posterior BA21/22), left middle frontal gyrus (BA6), the left anterior cingulate gyrus (BA24/32), and the right insula. Röder et al. (2002, p. 1011) conclude that "since other factors which affect sentence processing were held constant [...] and because we observed a modulation of inferior frontal cortex activity as a function of syntactic difficulty for both semantic and nonsemantic speech, our results are consistent with the proposal that the inferior frontal gyrus is essential for the "computation of grammatical transformations" [...] or more general, an online computation of the syntactic structure [...]." However, it seems to me that the crucial difference is not "length" of movement (long vs. short) or "difficulty" of type (neither of which are well defined), but rather a matter of different target domains as predicted by the Domain Hypothesis. Assuming the subject to be in the same structural position, namely, spec-IP, in all the examples, the "long'/"difficult" examples have movement of the two objects to a position above the subject (which marks the edge of the IP-domain), presumably a specifier position in an articulated CP-domain (Rizzi 1997). ${ }^{1}$ The 'short'/“easy" examples involve movement inside the VP-domain (or possibly to the IP-domain). The observed activation pattern, then, is the result of a 'scrambling-to$\mathrm{CP}>$ scrambling-below-CP' contrast.

Röder et al. (2002) also found activation in the right hemisphere homologue of Broca's area (R-BA44/45), but not as the result of a movement contrast. "Reliable right hemisphere activity was only obtained for lateral frontal cortex [i.e., RIFG, BA44/45] in the across-participants analysis for semantic vs. nonsemantic speech which is in agreement with the proposal that this region may be involved in the processing of semantic meaning as well” (Röder et al., 2002, p. 1011).

Fiebach et al. (2005) present results from an fMRI experiment on German scrambling in wh-questions as exemplified in (6) below (where a-d can be inserted in the underlined space), taking the distance (measured in number of words) between subject and object to be the relevant variable; "short-object" means that the clause-initial wh-object is immediately followed by the subject, and "long-object" means that the adverbials intervene between the fronted wh-object and the subject. Likewise, "short-subject" means that the clause initial wh-element is the subject and that it is immediately followed by the object, whereas "long-subject" means that the two adverbials intervene between the fronted $w h$-subject and the object.

(6) Thomas fragt sich wen Obj $\left._{\text {der Doktor }}\right]_{\text {Subj }}[\text { am Dienstag nachmittag }]_{\text {Adv1 }}[$ nach dem Unfall] $]_{\mathrm{Adv} 2}$ verständigt hat

Thomas asks SELF who.ACC [the.NOM doctor] [on Tuesday afternoon] [after the accident] called has

"Thomas asks himself who the doctor called on Tuesday afternoon after the accident."

When comparing "long-object" and "short-object", Fiebach et al. (2005) found that the "long-object" wh-questions increased activation in BA44/45 (Broca's area) and BA21/22

\footnotetext{
${ }^{1}$ Some linguists, e.g. Haider (1997, 2003, p. 207), have argued that German does not have an IP-domain, only the CP- and VP-domains. See e.g. Vikner (2001, p. 87, 143) for arguments in favor of IP in German.
} 
(Wernicke's area, Middle STG) bilaterally. They did not find activation in any of these areas as the result of "long" vs. "short-subject".

Fiebach et al. (2005) do not provide the relevant syntactic analysis of the example sentences. I propose the (partial) analysis in (7). Rather than attributing the observed activation to differences in "length" of distance between subject and object, I suggest it is due to scrambling of the adverbials. Again I assume the subject to occupy spec-IP. In the "short-object" condition, the adverbials are adjoined to VP. In the "long-object" condition, the two adverbials scramble to a position above the IP-domain (arguably to specifiers of functional heads in an articulated CP-domain), that is, higher than IP, which is predicted by the Domain Hypothesis to increase activation in Broca's area.
a. $[\mathrm{CP} w h-\mathrm{Obj}$
[IP Subj [vp Adv1 Adv2 $t$ Verb Aux]]]
("short-object")
b. [CP wh-Obj Adv1 Adv2 [IP Subj [vP $t \quad t \quad t$ Verb Aux]]]
("long-object")

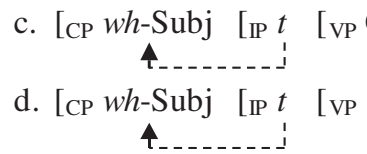
Verb Aux]]]
("short-subject")
("long-subject")

Under the structural analysis in (7), the absence of a difference in activation between "long" and "short-subject" is also explained. In both conditions, the $w h$-subject is in spec$\mathrm{CP}$ and there is no reason to assume that the object is scrambled higher than to a position adjoined to VP (or to some projection in the IP-domain) above the two adverbials. Thus, apart from the $w h$-subject, there is no additional movement to the CP-domain and under the Domain Hypothesis there should not be increased activation in Broca's area. The difference between "long" and "short-subject" does not (necessarily) include a difference in domain; both have movement to the edge of VP (or possibly into the IP-domain).

Grewe et al. (2005) present the results from an fMRI study on German scrambling of pronominal and nonpronominal objects, modeled on examples such as (8). In German, pronominal elements (in the unmarked case) precede full-DP (nonpronominal) objects and subjects. That is, there is a constraint on the linear order of constituents. The results revealed that only changes in the order of nonpronominal constituents increased activation in Broca's area. Contrasting sentences where a pronominal IO precedes a full-DP subject with sentences where a pronominal subject precedes a full-DP IO did not result in increased activation in Broca's area. They conclude that "the predictions of WM-based and transformation-based accounts of Broca's area function thus are not borne out. Rather, our results suggest that the pars opercularis (part of Broca's area) is selectively sensitive to the language-specific linearization of hierarchical linguistic dependencies [...]" (Grewe et al., 2005, p. 188). However, though I agree with the first part of their conclusion, I shall argue that the results are also accounted for by the Domain Hypothesis.

(8) Dann hat $[\text { der Lehrer }]_{\text {Subj }}[\text { dem Gärtner }]_{\text {IO }}[\text { den Spaten }]_{\text {Do }}$ gegeben

Then had the.NOM teacher the.DAT gardener the.ACC spade given

"Then the teacher had given the spade to the gardener." 
The authors do not provide structural analyses. However, pronominals are normally taken to occupy a specific (fixed) position in the structure, the 'Wackernagel position' (cf. Johnson, 1991; Müller, 2001; Platzack, 1998, p. 137). Assuming that the order of projections in the clausal backbone structure is universal, this position is the same as the one that pronominal objects move to in Danish where pronouns follow the subject in specIP (Vikner, 2005). The target of pronominal movement is a position between the canonical subject position, spec-IP, and NegP housing sentential negation, also part of the IPdomain. What I prose, then, are the structures in (9). If it is assumed that the constraint on linear order has higher priority than the requirement that the subject moves to spec-IP, the subject then occupies a lower position when preceded by pronominal objects, as in (9)a (constituents are pronominal if marked with subscript 'pron', otherwise full-DPs). ${ }^{2}$ When the subject is pronominal, it moves through the position for pronominals on the way to the subject position, spec-IP, as in (9)b. Provided that these empirically and theoretically based assumptions are correct, the observed lack of activation in the subtraction result follows from the Domain Hypothesis: the target of movement in both structures is in the IPdomain.
a. Adv Aux
[IP
$\mathrm{IO}_{\text {pron }}[$ Subj $t$
DO Verb]]
b. Adv Aux

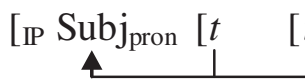
c. Adv Aux
[IP Subj
O
DO Verb]]
d. Adv Aux

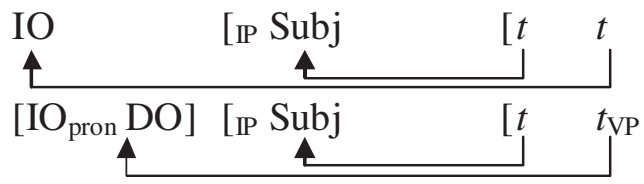
DO Verb]]
DO Verb]]
e. Adv Aux
Verb]]

Likewise, contrasting sentences such as (9)b with sentences with a full-DP subject preceding a full-DP IO, as in (9)c, did not increase activation in Broca's area. Again, this result is predicted by the Domain Hypothesis because both pronominal and full-DP subjects move to the same position, namely, spec-IP.

When subtracting (9)c from (9)d, on the other hand, the result did show increased activation in Broca's area. This is accounted for in the same way as with the results in Röder et al. (2002) and Fiebach et al. (2005), namely by assuming that the subject is in spec-IP and that the scrambled IO in (9)d has moved to a position in the CP-domainexactly what the hypothesis predicts to increase activation in Broca's area.

Finally, moving both the indirect and the DO together, as in (9)e, showed significantly more activation than (9)c and (9)a-both of which have movement to the IP-domain. It did not, however, differ significantly from the sentences where a nonpronominal IO has been scrambled in front of the subject, (9)d. Following Larson (1988) and Vikner (1989), I

\footnotetext{
${ }^{2}$ This constraint is a constraint on spell out. In the syntax, it could be assumed that the subject moves to a position below the Wackernagel-position (and below negation), say, spec-TP, and as spec-IP would still have to be filled, the phonological features of the subject DP is stranded in spec-TP while the formal features of the subject moves covertly to spec-IP. Thus, spec-IP contains a silent (nonovert) version of the subject. In this way, both syntactic and phonological requirements are satisfied.
} 
assume that double object shift involves the (lower) VP shell containing both objects. As the movement in (9)e involves nonpronominal material, it does not move to the designated pronoun position but undergoes scrambling to a position above the subject, i.e. to $\mathrm{CP}$. The fact that (9)e did not differ from (9)d follows from the fact that both crucially involve scrambling into the CP-domain above the subject.

Wartenburger et al. (2004) could be taken to be a counterexample to the proposed correlation between Broca's area activation and movement to $\mathrm{CP}$. They found that "noncanonical" > "canonical" word order did not result in activation in Broca's area. Instead, the effect was found in Wernicke's region (BA21/22/41/42) bilaterally. However, the linguistic conditions are internally too heterogeneous. In their "noncanonical" condition they conflate mono-clausal object wh-questions (movement to $\mathrm{CP}$ ) and embedded object-to-subject raising (movement to embedded IP), as well as two ungrammatical types, namely, adjunct $w h$-extraction across an argument $w h$-element in the embedded CP (movement to matrix CP) and raising across an unlicensed expletive in the embedded clause (movement to matrix IP). In the "canonical" condition, they include embedded infinitives and embedded 'standard' transitives, as well as two ungrammatical types, namely, examples with a personal pronoun used as an expletive (superfluous argument without a thematic role) and examples with case violations (accusative instead of dative). In my opinion, there are simply too many parameters that are not kept constant, and it is not clear what the result of their "canonicity" effect actually shows. For the same reason, their "grammaticality" effect (which conflates thematic and case violations) is not conclusive and cannot be used as an argument for or against the Domain Hypothesis. Furthermore, the Domain Hypothesis does not predict increased activation in Broca's area (and elsewhere) as the result of (non-) canonicity per se. Such increased activation is predicted only when there is movement to the CP-domain in one condition but not in the other in a subtraction.

In summary, there is variation but, more importantly, also consistency, see Table 1; all the studies of movement targeting the CP-domain show activation in Broca's area, with or without activation in one or more of the other areas of the distributed syntax network (Ben-Shachar et al., 2003, 2004; Dogil et al., 2002; Fiebach et al., 2005; Grewe et al., 2005; Röder et al., 2002). Furthermore, absence of activation in Broca's area in movement contrasts can be attributed to the fact that the movements target other domains. Röder et al.'s (2002) semantic well-formedness condition relates to the VP-domain and showed activation in the right BA44/45; VP-internal dative shift in Ben-Shachar et al. (2004) activated the right frontal area in the vicinity of IFG (R-vPrCG and insula); the "short vs. long subject" contrast of Fiebach et al. (2005) targets VP or IP and did not result in activation in the relevant areas. Likewise, pronominal scrambling to IP in Grewe et al. (2005) did not activate Broca's area. The lack of difference in activation between subject and object relatives (Ben-Shachar et al., 2004; not shown in Table 1), can be attributed to the fact that both target spec-CP.

\section{The present study}

The focus of the present fMRI experiment is on two different types of operator movement. (Operators are scope-bearing elements such as quantifiers, e.g. all and some, negation, e.g. not, and wh-elements, such as who and what). The first one, NEG-shift (Christensen, 2005), is the movement of a negative indefinite quantified object to the 
position of negation in the middle of the clause, i.e. in the IP-domain, in order to license sentential negation. The construction is complementary to the corresponding construction with a version of not any. NEG-shift is observed in Danish as well as in many other Germanic and nonGermanic languages, such as Icelandic, Polish, and Hungarian, but not, for example, in English and French (with very few exceptions). Note that in Danish the negated object headed by ingen 'no' precedes the main verb fundet 'found', whereas the canonical object position is after the verb.
a. Politiet havde ikke fundet [nogen beviser]
Police. the had not found any evidence. PLUR
b. Politiet havde [ingen beviser] fundet $t$
Police the had no evidence. PLUR found

The second type of movement is $w h$-movement to spec-CP:

(11) a. Havde politiet ikke fundet [nogen beviser]?

Had police. the not found any evidence.PLUR

b. [Hvilke beviser] havde politiet ikke fundet $t$ ?

Which evidence.PLUR had police. the not found

As is evident from the examples, the canonical position, or the 'base-position', of the object is the same throughout, whereas the position the object moves to, the target position, in the two types of constructions is different. The two types of syntactic movement have different motivations/triggers: NEG-shift is motivated by sentential negation and $w h$-movement by interrogative force.

\subsection{Materials and methods}

\subsubsection{Subjects}

Twenty male native speakers of Danish, aged between 21 and 38 years $($ mean $=30.0)$ participated in the study. They were all right handed with no medical history of mental deficits or neurological trauma.

\subsubsection{Stimuli}

As illustrated in Table 2, the experiment is based on a 2-by-2 factorial design. The first factor or parameter is \pm movement of a syntactic operator, the second is target domain (IP or $\mathrm{CP}$ ). In the + movement conditions, the moving operator is either the negative object undergoing NEG-shift, condition (A), or the wh-object in a wh-question, condition (C). In the -movement conditions, the nonmoving (directly inserted) operator is either the negative adverb ikke 'not', condition (B), or the phonologically silent/nonovert (but syntactically real) interrogative operator in a yes/no-question, condition (D). In conditions (A) and (B) the target of movement in the former and insertion in the latter is spec-NegP located in the IP-domain. In conditions (C) and (D) the target of movement and insertion, 
Table 2

Experiment parameters and stimulus examples

\begin{tabular}{lll}
\hline & Well formed & Anomalous \\
\hline$(\mathrm{A}):+$ Move $\rightarrow$ IP & Konen har vist ingen sko haft & Konen har vist ingen ideer spist \\
& Wife-the has I-guess no shoes had & Wife-the has I-guess no ideas eaten \\
$(\mathrm{B}):-$ Move $\rightarrow$ IP & Wonen har ikke haft nogen sko & Konen har ikke spist nogen ideer \\
& Hvilke sko har konen ikke haft? & Wife-the has not eaten any ideas \\
$(\mathrm{C}):+$ Move $\rightarrow \mathrm{CP}$ & Which shoes has wife-the not had & Hvilke ideer har konen ikke spist? \\
& Har konen ikke haft nogen sko? & Which ideas has wife-the not eaten \\
& Has wife-the not had any shoes & Har konen ikke spist nogen ideer? \\
& & Has wife-the not eaten any ideas \\
\hline
\end{tabular}

respectively, is spec-CP. Each condition was constructed both as well-formed sentences and semantically anomalous sentences. The relevant partial syntactic representation of the four types is given in (12).

(12) (A) [CP Subj $\mathbf{1}_{1}$ Aux $2\left[\mathrm{IP}_{1} \mathrm{t}_{2}\left[\mathrm{Adv}\left[\mathrm{NegP}[\text { ingen NP}]_{3}\left[\mathrm{VP}_{2}\left[\mathrm{vP}_{1} \mathrm{t}_{1}\right.\right.\right.\right.\right.$ Verb $\left.\left.\left.\left.\left.\mathrm{t}_{3}\right]\right]\right]\right]\right]$

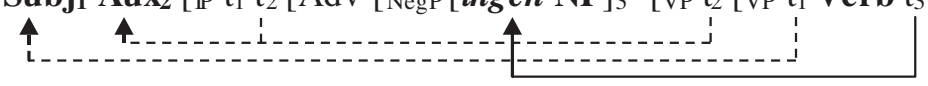

(B) $\left[{ }_{\mathrm{CP}} \mathbf{S u b j}_{\mathbf{1}} \mathbf{A u x}_{2}\left[\mathrm{IP}_{1} \mathrm{t}_{2} \quad[\mathrm{NegP} \boldsymbol{i k k e}\right.\right.$

$\left[\mathrm{vP}_{1} \mathrm{t}_{2}\left[\mathrm{vP} \mathrm{t}_{1}\right.\right.$ Verb [nogen NP]]]]]]

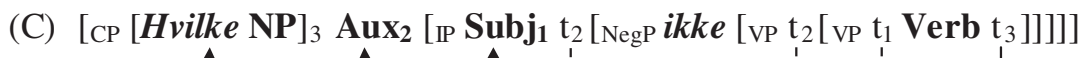

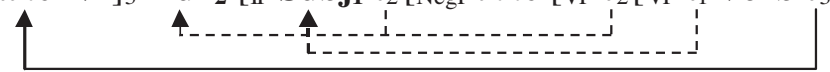

(D) ${ }_{\mathrm{CP}} \mathbf{O P}$

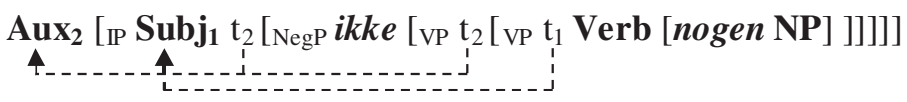

In the anomalous sentences, either the object $(53.33 \%)$ or the subject $(46.67 \%)$ induced a semantic (not syntactic) violation of the selection restrictions of the verb, e.g. with korn 'seed' as the object of høre 'hear' or ideer 'ideas' as the object of spise 'eat', or with asken 'the box' as the subject of finde 'find' or fuglen 'the bird' as the subject of købe 'buy'. The ratio between well-formed and anomalous sentences was 3:1 (25\% anomalous) in order to avoid chance bias (i.e. guessing).

All sentences contained six words to avoid bias due to different number of words. All were constructed in the present perfect tense, namely, with the auxiliary har 'has' and the perfect participle of a main verb.

All conditions are constructed using the same lexical material as far as possible; some elements such as ingen, vist and hvilke are by necessity unique to certain conditions. In the (A) condition (NEG-shift), an additional adverb had to be inserted in order to make it six words long. In all the (A) sentences this adverb was vist, a small discourse particle-like adverb meaning something like 'I guess' or 'it seems'. (Admittedly, this is a potential weakness as the lexical item should have been varied in the sentences to even out any potential lexical influence). Otherwise, contrasts were kept as minimal as possible in order to isolate the movement effects. 
In addition to the four linguistic task conditions, the experiment included a 'dummy' condition where the subjects did not have to do anything but watch numbers count down from 4 to 1 . This was included to avoid fatigue.

\subsubsection{Presentation}

The stimuli were presented in blocks of four sentences of the same type (A, B, C, or D). Within each block, 0,1 , or 2 sentences were anomalous. There were 15 blocks of each type (A, B, C, or D) which gives a total of 60 sentences (tokens) of each type (45 well formed and 15 anomalous per type), an overall total of 240 sentences (180 well formed and 60 anomalous).

During scanning, the sentences were presented visually, projected onto a screen with an interval of $4 \mathrm{~s}$ (event time $=4 \mathrm{~s}$ ). The subjects were asked to judge whether the sentences were well formed or anomalous and to press left or right, respectively, on a response box fastened to their right hand. The real parameter ( \pm movement) was thus 'hidden' in the sense that the subjects were not asked to attend to it.

In order to avoid any potential contextual confounds, the blocks were pseudorandomized, both internally (well-formed/anomalous sequences, semantic similarity, and subject/object anomaly) and externally (random order of block type).

The presentation software was tailor made for the experiment. It projected sentences onscreen aligned to the center with pre-specified intervals (event time $=4000 \mathrm{~ms}$ ); tests were made to ensure that the program ran in actual real time (an unexpected problem found on a number of different computers tried in the experiment). The text was set using the Arial font which is a clear-cut type (sans serif) with no ornamentation. The program recorded the subjects' responses (marking whether the actual response is the same as the predicted response) as well as reaction times. During the first $700 \mathrm{~ms}$, response was suppressed in order to make sure that the response (right or wrong) could not be attributed to a 'spill over' from the previous event. For example, if a subject responds 'OK' to event one and keeps pressing or holding down the response button, the same response will be given to event two once the time window of $4 \mathrm{~s}$ has passed and the next event begins. Suppression time was based on pre-experimental test runs where response time never went below $700 \mathrm{~ms}$.

\subsubsection{Data acquisition}

The experiment was performed at the MR Research Center, Skejby Sygehus, Aarhus University Hospital, Denmark, on a GE Horizon Echospeed LX 1.5 Tesla clinical MR scanner (Signa SR120).

The fMRI scan volume consisted of 40 axial slices (thickness $=3 \mathrm{~mm}$, spacing $=0$ ) covering the entire cerebrum and cerebellum. FOV $=64 \times 64$ voxels, in-plane resolution $=2 \times 2 \mathrm{~mm}$. Flip angle $=70, \mathrm{TE}=30.4, \mathrm{TR}=3 \mathrm{~s}$.

Total fMRI scan time $=20 \mathrm{~min}$ resulting in 400 full brain volumes per subject. In addition, at the beginning of each fMRI session, eight dummy acquisitions were made to allow the magnetic field to get into alignment.

\subsubsection{Data analysis}

The imaging data was analyzed with SPM2 (Statistical Parametric Mapping, Wellcome Department of Imaging Neuroscience, University College London). The imaging data were realigned to correct for movement, normalized to the Talairach Space 
(Talairach \& Tournoux, 1988), and smoothed with a kernel of $7 \mathrm{~mm}$ ) to correct for random variation in signal intensity. Activation clusters were analyzed using the MNI Space Utility (The PET Lab, Institute of the Human Brain, St. Petersburg, Russia). All subtractions are random-effect analyses with a significance threshold set to $p<0.001$, uncorrected for multiple comparisons given the anatomically constrained hypothesis of the distributed syntax network. The analysis below includes only activations that are significant $(p>0.05)$ at the cluster level (with one important exception, namely, BA44/45).

\subsection{Results}

\subsubsection{Behavioral results}

Veridicality, the possibility of having a truth value, did not influence judgments. Anomalous sentences were judged as such, regardless of the fact that many of them are always true (for example, she did not eat any ideas is always true because ideas are not edible). That is, subjects systematically responded as predicted (well formed: $91.33 \%$ correct, anomalous: $94.67 \%$ ), though significantly better on the anomalous examples $(p=0.17)$.

The differences in correct performance between (A), NEG-shift, and (B), NEG-adv, and between (C), wh-question, and (D), yes/no-question, were not significant ( $p>0.57$ and $p>0.93$, respectively). Neither was the difference between + Movement, $(\mathrm{A}+\mathrm{C})$, and -Movement, $(\mathrm{B}+\mathrm{D}),(p>0.41)$. Furthermore, there were no significant differences in reaction time ((A) vs. (B): $p>0.37$; (C) vs. (D): $p>0.50$; $(\mathrm{A}+\mathrm{C})$ vs. $(\mathrm{B}+\mathrm{D}): p>0.88)$. As there are no significant differences in performance or in reaction time between the four conditions, it seems safe to conclude that there is no difference in task difficulty either (difficulty is held constant). Put differently, the imaging results cannot be attributed to differences in task difficulty or processing time, and with all other factors kept as constant as possible, it is reasonable to assume that the isolated effect in the imaging results is attributable to syntactic movement in the linguistic input.

\subsubsection{Imaging results}

The subtraction results are summarized in Table 3.

2.2.2.1. Main movement effect. The main movement effect (AC>BD) reveals increased activation in the right cerebellum, left anterior and posterior middle temporal gyrus (BA21), and left inferior frontal gyrus (Broca's area, BA45), see Fig. 4 (top row). It is reasonably clear that the effect is compatible with the distributed syntax network.

The activations in Broca's area and anterior BA21 do not reach the cluster level of significance $(p<0.05)$. However, small-volume-correction analyses using WFU (Wake Forest University School of Medicine) Pickatlas (Maldjian, Laurienti, \& Burdette, 2004; Maldjian, Laurienti, Kraft, \& Burdette, 2003) referencing in the aal atlas (TzourioMazoyer et al., 2002) show that the activations are significant ( $p<0.05$ FDR).

(The opposite subtraction $(\mathrm{BD}>\mathrm{AC}),-$ Movement $>+$ Movement, reveals no significant activation clusters).

2.2.2.2. Wh-movement. The result of subtracting condition (D), yes/no-questions, from condition (C), wh-questions, resembles the main effect, see Fig. 4 (mid). The contrast reveals increased activation in the right cerebellum, in Broca's area (BA45), and in the left 
Table 3

Clusters specifications

\begin{tabular}{lllll}
\hline Contrast & Activation site & $\begin{array}{l}\text { Cluster level } \\
\left(p_{\text {Corrected }}\right)\end{array}$ & $\begin{array}{l}\text { Size } \\
\text { (voxels) }\end{array}$ & Local max. $(x, y, z)$ \\
\hline Main effect (AC $>$ BD) & R-Cerebellum & 0.017 & 210 & $32,-84,-34$ \\
& L-aMTG (BA21) & $0.018^{\mathrm{a}}$ & 119 & $-54,-4,-14$ \\
& L-pMTG (BA21) & 0.012 & 227 & $-60,-18,-12$ \\
& L-IFG (BA45/46) & $0.048^{\mathrm{a}}$ & 55 & $-58,26,12$ \\
Wh-movement $(\mathrm{C}>$ D) & R-Cerebellum & 0.003 & 295 & $24,-88,-38$ \\
& L-pSTG/TOP (BA22/39/19) & 0.002 & 317 & $-42,-54,18$ \\
NEG-shift $(\mathrm{A}>\mathrm{B})$ & L-IFG (BA44/45/46) & $0.023^{\mathrm{a}}$ & 87 & $-58,26,12$ \\
Interaction $(\mathrm{C}>\mathrm{D})>(\mathrm{A}>\mathrm{B})$ & L-aMTG/STG (BA21/38) & 0.001 & 361 & $-60,-2,-20$ \\
Interaction $(\mathrm{A}>\mathrm{B})>(\mathrm{C}>\mathrm{D})$ & L-pSTG/TOP (BA22/39/19) & 0.002 & 267 & $-52,-58,16$ \\
& & 0.001 & 321 & $-40,4,-22$ \\
\hline
\end{tabular}

L, left; R, right; IFG, left inferior frontal gyrus, a/pMTG, anterior/posterior middle temporal gyrus, (a/p)STG, (anterior/posterior) superior temporal gyrus; TOP, Temporal-Occipital-Parietal junction.

${ }^{\text {a }}$ Small volume correction $p_{\mathrm{FDR}}$.

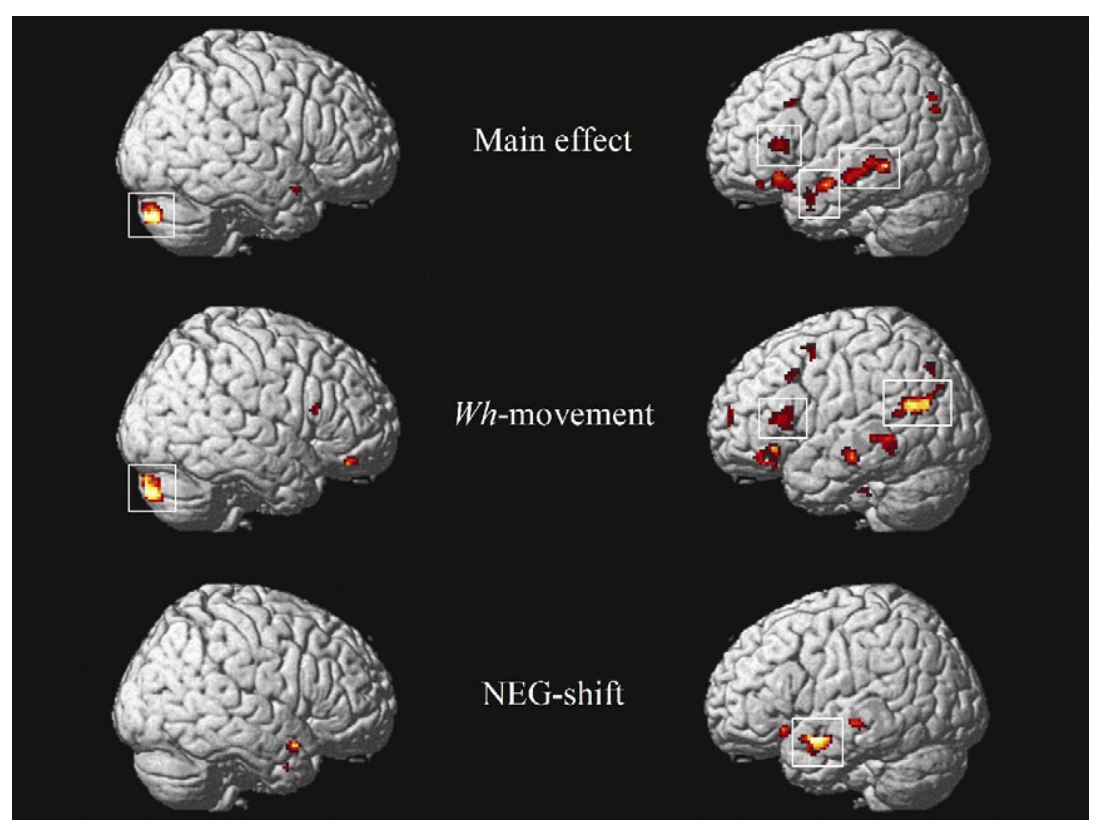

Fig. 4. Movement contrasts.

Temporal-Occipital-Parietal Junction (BA22/39/19) which includes Wernicke's area, the angular gyrus, and the supramarginal gyrus, see Table 3 and Fig. 5.

Again the activation in Broca's area does not reach the cluster level of significance, and again, a small-volume-correction analysis shows that the activation is significant $(p<0.03$ FDR). 


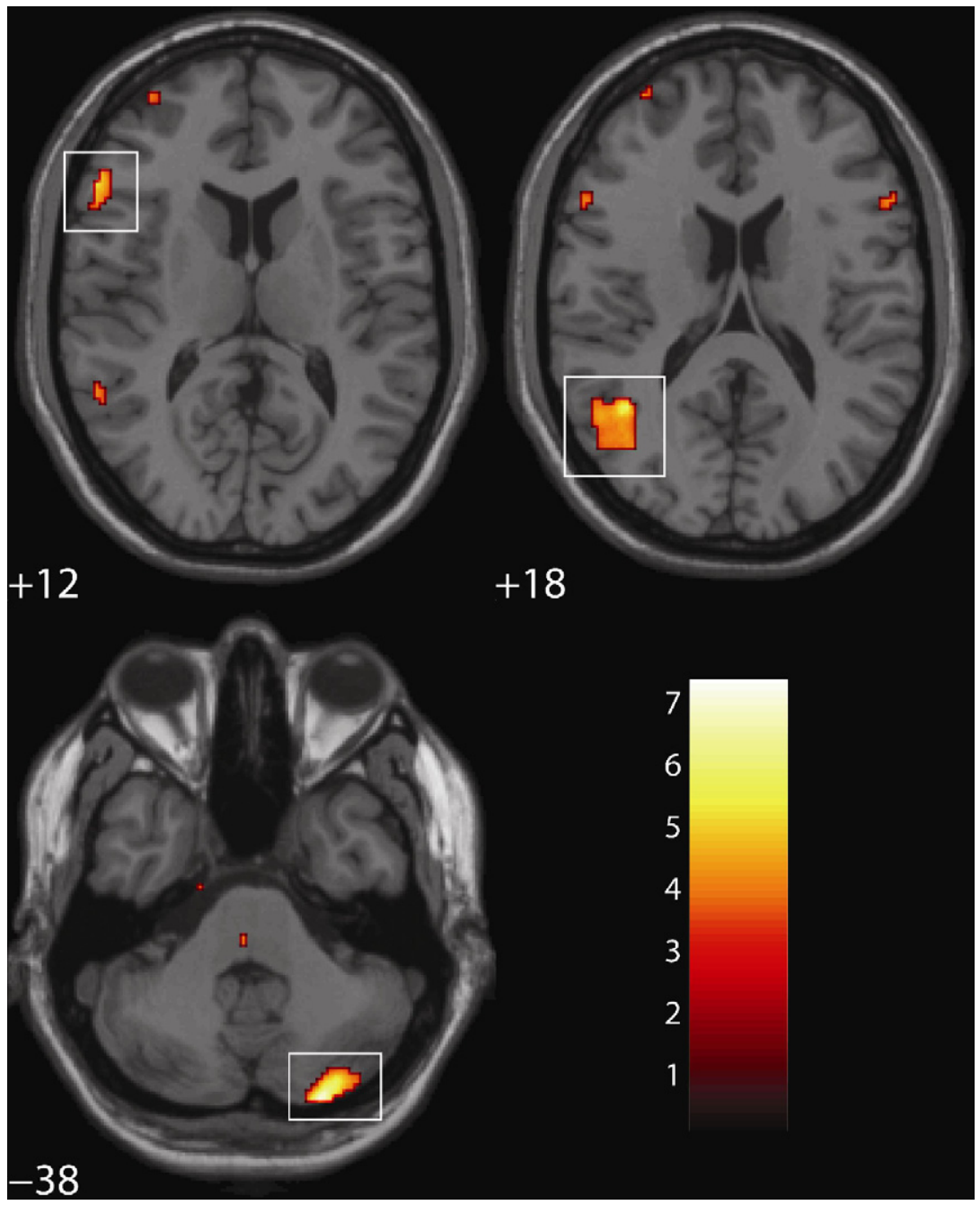

Fig. 5. Wh-movement $(\mathrm{C}>\mathrm{D})$.

It is interesting that the activation includes the angular gyrus (BA39) which is anomia, a lexico-semantic naming deficit (not a syntactic deficit) in which comprehension as well as production is relatively intact (the problem lies in lexical retrieval), unlike Wernicke's aphasia where comprehension is impaired (Damasio, 1992; Pinker, 1994). There is no lexical difference between conditions (C) and (D) except for hvilke 'which' with the partial feature composition [Indef, Quant, Wh] (i.e. it is an indefinite quantifier and a question marker) in (C) vs. nogen 'any' with the partial feature composition [Indef, Quant] in (D). In the latter, the [Wh] feature is inserted on the empty operator OP in spec-CP. It could be argued that that the activation in the posterior language regions reflects this difference in feature realization, or simply the overt lexical difference. However, if that were the case, the prediction would be that the same activation should result from the NEG-shift 
subtraction in the next section (with ingen 'no' [Neg, Indef, Quant] vs. ikke [Neg]+ nogen [Indef, Quant]) which is not borne out.

(The opposite contrast $(\mathrm{D}>\mathrm{C})$, which is more active in yes/no-questions than in whquestions, reveals no significant activation clusters).

2.2.2.3. NEG-shift. Subtracting (B), clauses with a negative adverbial operator (and object in situ), from (A), NEG-shift, reveals only a single large cluster in the left anterior middle and superior temporal gyrus (BA21/38), see Fig. 4 (bottom) and Fig. 6.

(The opposite contrast, that is (B) NEG-adv (ikke) $>$ (A) NEG-shift (ingen), revealed no significant activation clusters).

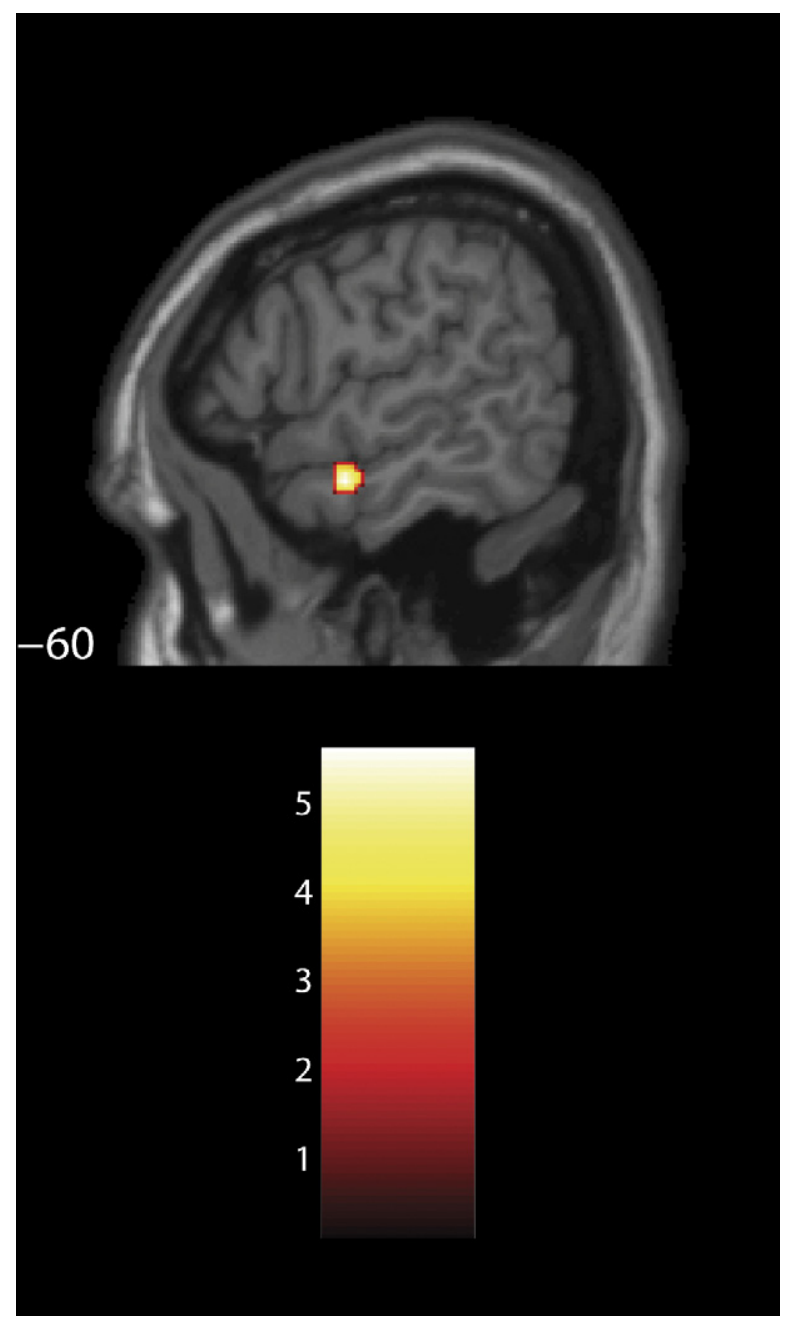

Fig. 6. NEG-shift $(\mathrm{A}>\mathrm{B})$. 
2.2.2.4. Movement $\times$ target interaction effect. Perhaps the most important contrast is the one that measures the actual interaction effect between movement and target domain, i.e. $((\mathrm{C}>\mathrm{D})>(\mathrm{A}>\mathrm{B}))$, and it reveals a large cluster in the left posterior temporal gyrus and Temporal-Occipital-Parietal Junction (BA22/39/19). The reverse subtraction $((\mathrm{A}>\mathrm{B})>$ $(\mathrm{C}>\mathrm{D}))$ reveals a single large activation cluster in the left anterior superior temporal gyrus (BA38). See Fig. 7.

\section{Discussion}

The results of the present fMRI study are summed up in Table 4. Of the three activation clusters in the main movement effect $w h$-movement is responsible for the activation in

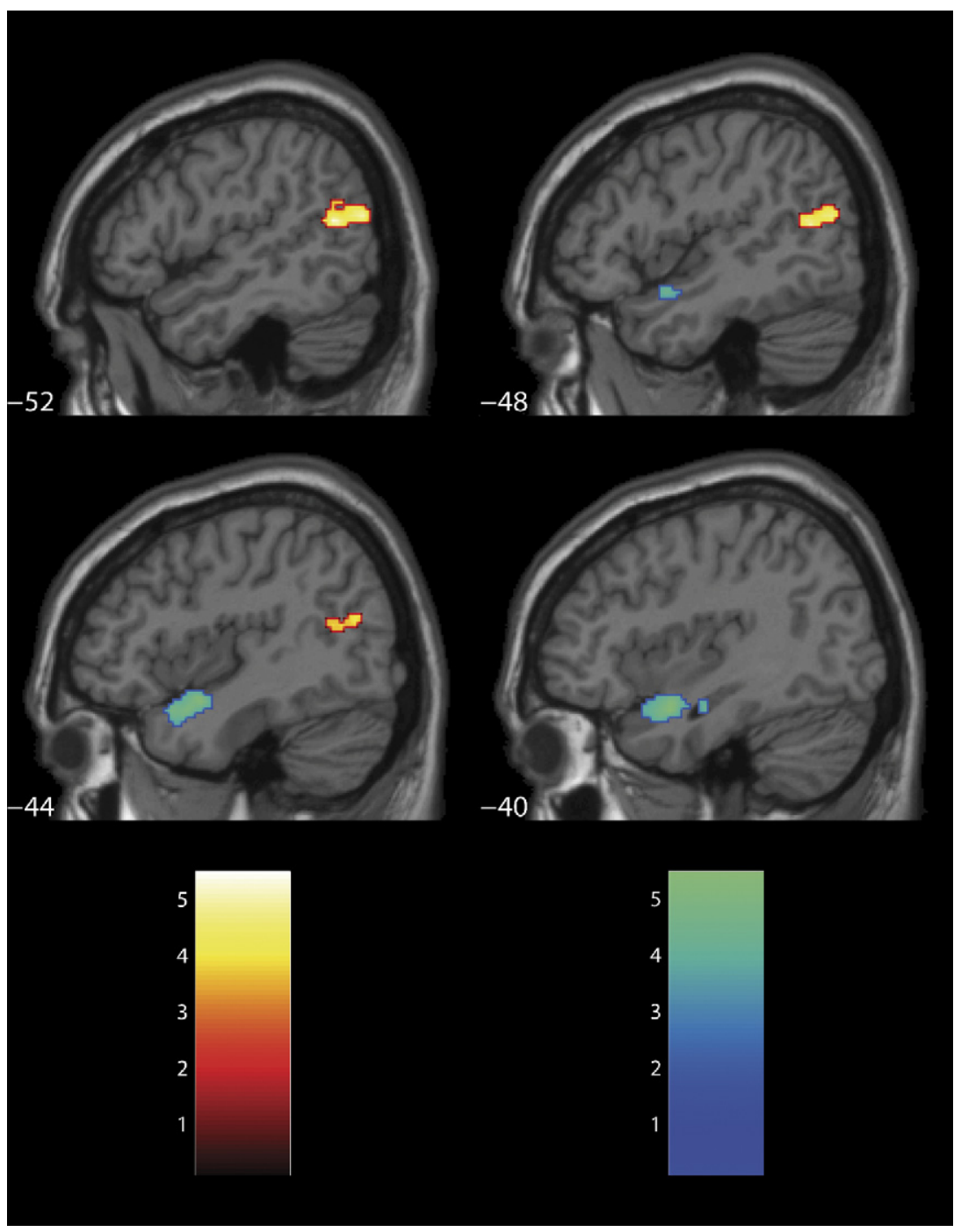

Fig. 7. Interaction effects. Red/yellow $=((C>D)>(A>B))$, blue $/$ green $=((A>B)>(C>D))$. 
Broca's area and the activation in the right side of cerebellum. NEG-shift contributes to the movement effect in the left anterior middle temporal gyrus. Importantly, only movement to CP induces activation in Broca's area. These results show that not only does it matter whether or not there is syntactic movement; it is also crucial what the actual target is. That is, the results support the Domain Hypothesis and show an interaction between movement and target domain. Interestingly, however, the interaction contrasts do not show any involvement of Broca's area. Instead, the interaction contrasts show involvement of the Temporal-Occipital-Parietal Junction and the left anterior superior temporal cortex. Crucially, the two movements result in different activation patterns; in fact, they show no overlapping activation.

Wh-movement also induces activation in the posterior part of the superior temporal gyrus. This is in accordance with six of the eight studies of movement to CP in Table 1. The anterior temporal activation induced by NEG-shift is not reported in any of the movement studies discussed above (see Table 1).

Further support for the Domain Hypothesis and the distributed syntax network comes from lesion studies. Studies of aphasia have shown that the core combinatorial aspects of language are normally left lateralized (cf. e.g. Damasio, 1992; Grodzinsky, 2000). Aphasia due to right-hemisphere damage is very rare and only if the patient suffers from early left hemisphere damage (cf. Bishop, 1988). It appears, then, that the processes of syntactic computation crucially involve areas in the left hemisphere, though the computation of syntactic representations, i.e. interfacing between syntax and with other cognitive systems, activates a much more distributed network.

Right hemidecortication and right-hemisphere lesions lead to pragmatic disorders, such as problems with understanding narratives, humor, and jokes (cf. Damasio, 1992, p. 537; Deacon, 1997; Paradis, 1998; Schneiderman \& Douglas, 1988 and references cited there). Patients with right-hemisphere damage understand the lexical and syntactic elements, the individual words and phrases, showing that the deficit is neither lexical semantic nor syntactic per se. They have problems with recalling the main events of a narrative, remembering the sequence of events, and crucially, "the schematic assignment of actions to agents" (Donald, 1991, p. 82). What appears to be impaired, at least, is the ability to retain the roles of players in narratives. Even though this is at a supra-sentential level, it seems reasonable to assume that it also crucially dependent on the system needed for proper

Table 4

Summary of results

\begin{tabular}{llllll}
\hline & R-Cerebellum & $\begin{array}{l}\text { L-IFG } \\
(\mathrm{BA44} / 45)\end{array}$ & $\begin{array}{l}\text { L-pMTG } \\
(\mathrm{BA21})\end{array}$ & $\begin{array}{l}\text { L-pSTG/TOP } \\
(\mathrm{BA22} / 39 / 19)\end{array}$ & $\begin{array}{l}\text { L-aMTG/STG } \\
(\mathrm{BA21} / 38)\end{array}$ \\
\hline Main effect (AC $>$ BD) & + & + & & + \\
Wh-movement (C>D) & + & + & & + \\
NEG-shift $(\mathrm{A}>\mathrm{B})$ & & & & + \\
Interaction & & & & + \\
$(\mathrm{C}>\mathrm{D})>(\mathrm{A}>\mathrm{B})$ & & & \\
Interaction & & & \\
$(\mathrm{A}>\mathrm{B})>(\mathrm{C}>\mathrm{D})$ & & & \\
\hline
\end{tabular}

L, left, R, right; IFG, left inferior frontal gyrus; a/pMTG, anterior/posterior middle temporal gyrus; a/pSTG, anterior/posterior superior temporal gyrus; TOP, Temporal-Occipital-Parietal junction. 
intra-sentential assignment of thematic roles. (See also Brownell, 2000, for a discussion of the role of the right hemisphere in understanding metaphors). Lesions in the right homologue of the language areas may also lead to prosodic impairments, in production as well as comprehension (cf. Calvin \& Ojemann, 1994, chapter 4; Donald, 1991, p. 80; Schneiderman \& Douglas, 1988).

The deficits associated with right-hemisphere damage are clearly neither (core) syntactic, (lexical) semantic, phonological, nor phonetic per se. The core systems of language are intact. That is, the right side may not be crucially needed for the computation of linguistic structure but it plays a crucial role in the interfacing between the computational system and higher cognitive systems, including thematic representation.

Within the left hemisphere, the 'classical' language areas, Broca's and Wernicke's areas, have been associated with syntax and semantics, respectively. However, neither the 'syntax in Broca's area' nor the 'semantics in Wernicke's area' hypotheses hold under scrutiny. The results of the neuroimaging studies in reviewed above as well as the data from the resent study show that Wernicke's area is also activated in some, but far from all, syntactic tasks. Furthermore, not all syntactic processing increases activation in Broca's area and not all of syntax is impaired in Broca's aphasia.

Lesions in Wernicke's area do not normally result in syntactic deficits. Rather, it appears that there is a correlation between lesions to Wernicke's area and its vicinity and semantic deficits (cf. Damasio, 1992; Pinker, 1994; Grodzinsky, 2000). Lesions in Wernicke's area itself result in Wernicke's aphasia (severely impaired comprehension, but more or less grammatical and "fluent" production characterized by lack of sense and frequent neologisms and word substitutions); lesions in the supramarginal gyrus result in conduction aphasia, a deficit involving phonemic paraphasia, word substitution, naming problems, and lack of capacity for verbatim repetition, but with relatively preserved comprehension; lesions in the angular gyrus lead to anomia, a naming deficit with normal comprehension and no severe substitutions of words or inflections. According to Fuster (2003, p. 73), this region, the Temporal-Occipital-Parietal Junction, is a multimodal association convergence region. These findings together suggest a role for Wernicke's area in lexical retrieval, looking up words in the mental lexicon and sending them on to other areas of the grammar. (The lexicon itself is distributed over much larger areas, if not the whole brain). This function is clearly needed for semantics but it is also required in syntax, for example in selection and projection in the implementation of argument structure.

Thus, even though Wernicke's area has been found to be active in neurosyntactic studies (see also Friederici, Rüschemeyer, Hahne, \& Fiebach, 2003), the involvement is not consistent. In the studies in Table 1, some of the movements activate it, but not all of them, and the same holds for the present study, see Table 4.

The central role of Broca's area in neurosyntax is motivated by the fact that lesions to Broca's area (BA44/45) lead to Broca's aphasia characterized by agrammatism: 'telegraphic' speech on the production side (e.g. Friedmann, 2003; Friedmann \& Grodzinsky, 1997) and problems with comprehending semantically reversible sentences with syntactic movement that affects the order of theta-roles (e.g. Grodzinsky, 1986, 1990, 1995a, b, 2000, 2006). That is, Jack kissed Jill is unproblematic, whereas Jill was kissed by Jack leads to chance performance. Van der Meulen (2004), based primarily on data from her studies on French agrammatism but also on data from studies on English agrammatism, argues that the syntactic deficit in agrammatism needs to be refined even further. She argues that $w h$-questions deviate from the standard subject/object asymmetry 
in agrammatism as there is no significant difference between object and subject whquestions; in both performance is significantly impaired but above chance. However, French Broca patients' comprehension of object questions with wh-in-situ is significantly better than comprehension of subject and object wh-questions with movement (est-ce que, glossed as ' $\mathrm{Q}$ ', is argued to be an interrogative marker occupying $\mathrm{C}^{\circ}$ and is obligatory in object questions but optional in subject questions) (examples based on van der Meulen, 2004, p. 81, (5)):

a. $[\mathrm{CP}$ The boy splashes who?

[IP Le garçon arrose qui ]]? (Obj in situ)

b. [CP [Qui] est-ce que [IP le garçon arrose $t$

]]? (Obj moved)

Who $Q$ the boy splashes?

"Who does the boy splash (with water)?"

c. [CP [Qui] (est-ce que) [IP $t$

arrose le garçon ]]? (Subj moved)

Who $Q$ splashes the boy?

"Who splashes the boy (with water)?"

Van der Meulen (2004) argues that Broca's aphasics have significantly more difficulties comprehending structures with phrasal movement, such as wh-movement, than with structures with less or no such movement.

In clefts and relatives, in French as well as in English, the classic asymmetric pattern is observed, namely, that object relatives are more impaired than subject relatives. To account for this, van der Meulen (2004) proposes a revision of the standard analysis of these constructions such that only object relatives and clefts involve XP-movement. In subject relatives and clefts, the subject remains in the canonical subject position (cf. van der Meulen, 2004, p. 160, (46); 170, (67)):

I see the man

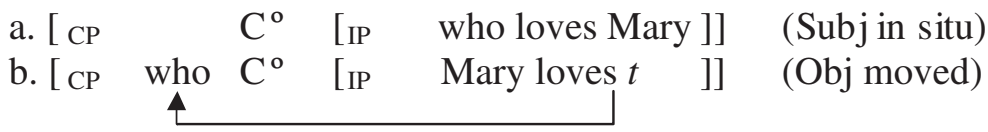

In summary, lesions in Broca's area lead to syntactic deficits indicating its crucial involvement in syntactic processing. However, as with the data in the neuroimaging studies, the correlation between Broca's area involvement and syntactic movement appears to be closely tied to the CP-domain.

According to Platzack (2001b), agrammatic performance on movement phenomena related to the CP-domain is "hampered". For example, V2 and obligatory finiteness: finite verbs are correctly placed in V2 position, whereas nonfinite errors are produced as root infinitives (see also Burchert, Swoboda-Moll, \& de Bleser, 2005); other examples are the obligatory subject and wh-movement. This holds at least for Swedish and German SLI children, children acquiring their L1, adults acquiring L2, and Broca's aphasics. The 
phenomena related to lower domains (such as verb-object order and particle-object order) are unaffected/target like.

The results from the present study together with the results from other imaging and lesion studies show that the neural implementation (neurological organization) of syntactic processing is not uniform. Syntactic processing is implemented in a distributed cortical network reflecting interfacing between syntax and other cognitive systems. An analysis in terms of general (undifferentiated) WM is, at best, difficult to maintain as WM is not uniform either. Syntax relies on different types of WM and derivation by phase is a WMsaving way of computation, both on the phonological and the semantic side, as well as in the syntactic structure building itself. Hence, this is not an argument against WM per se.

The Domain Hypothesis accounts for the data by stating that there is a movement $\times$ target domain interaction: The activation pattern depends on the target of movement. This explains both some of the variation in the data but also some of the consistency.

The fact that both VP- and CP-related movement shows frontal lobe effects is in line with the theoretical conception of these two syntactic domains, but not the IP-domain, as 'strong' phases (though clearly much more neuroimaging data on VP-internal movement is needed). It should be emphasized, however, that it does not, in any way, imply the nonexistence of IP or of movement operations targeting the IP-domain or their relevance to human sentence processing. The results of the present study, in fact, show that the activation should perhaps be searched for elsewhere, namely, in the temporal lobes.

The IP- and VP-domains are less vulnerable to brain damage in the language areas in left hemisphere than the CP-domain. In turn, IP is more vulnerable than VP as inflectional morphology is often affected in aphasia (cf. the Pruning Hypothesis, Friedmann, 2003; Friedmann \& Grodzinsky, 1997; Grodzinsky, 2000). The evidence seems to converge on the assumption that the CP, IP, and VP-domains are different, with regards to syntax, interpretation, as well as neurological implementation. As Platzack (2001b, p. 375) states, "a natural conclusion is that the theoretical unification of the I-domain and the C-domain [...] might not correspond to the neurological organization". Note, however, that it does not follow that the structural unification is invalid; on the contrary, in fact. This unification is based on massive empirical linguistic research on hundreds of languages as well as on purely theoretical considerations.

The Domain Hypothesis makes a number of empirical predictions for further empirical research. However, it should be stressed that these predictions are not problems for or weaknesses of the Domain Hypothesis; they are natural further empirical questions of the sort that any falsifiable scientific research raises. These predictions have to do with operations targeting the IP- and VP-domains.

NEG-shift targets spec-NegP in the IP-domain and comprehension of NEG-shift should be normal in Broca's aphasia, cf. that negation is generally rarely affected in agrammatism (Hagiwara, 1995; Lonzi \& Luzzatti, 1993, but see Bastiaanse, Rispens, Ruigendijk, Rabadán, \& Thomson, 2002).

As object shift targets an IP-internal position (Johnson, 1991; Müller, 2001; Platzack, 1998; Vikner, 2005), it should also be (relatively) unaffected in agrammatism and should not increase activation in Broca's area but perhaps increase anterior temporal activation.

Passivization (and raising in general) is movement to the IP-domain and the prediction is that it does not increase activation. However, German and Dutch agrammatics perform normally on passives (in accordance with the hypothesis that movement to IP does not 
require extra computation in Broca's area), whereas the performance of English agrammatics is impaired, cf. Drai \& Grodzinsky (2006). This could be taken to suggest that the subject in English may occupy a position in the CP-domain, contrary to what is standardly assumed, and that the correlation between passivization and Broca's area activation may be subject to language variation.

Furthermore, passivization involves a VP-internal change. The external argument (which may be the subject in active sentences) is suppressed or optionally right adjoined to VP and the internal argument (the 'underlying' object) moves to the position normally associated with the subject, the inner spec-VP (there is thus also a change in thematic role assignment to structural positions). Therefore, keeping in mind the sparse neuroimaging data on VP-internal operations, the right frontal region would also be expected to be involved.

Dative shift should not be affected in agrammatism, but could potentially be impaired by lesions in the IFG in the right hemisphere. Generally, thematic role assignment would be expected to be affected by damage to this region. As mentioned above, the understanding of jokes and humor and of the event structure in narratives are impaired after right hemisphere lesions and right hemidecortication. Whether or not processing of thematic information depends on a computational center in the right IFG, that is, whether or not focal brain damage in RIFG disrupts thematic role assignment (in a broad sense) remains to be investigated. If so, it should manifest itself in impairments in passivization and dative shift as well as in the pragmatic domain.

There is also a question about left-edge phenomena in general. Assuming, as is standard at least in minimalist syntax, that there is a strong parallel between the structure (and interpretation) of clauses, i.e. CPs, and DPs (see e.g. Haegeman \& Guéron, 1999, pp. 411-446 for discussion). Arguably then, like CPs, DPs are also strong phases (cf. Chomsky, 2001, p. 14, in press, p. 9 and references cited there). The question is whether movement to the left edge of DP, that is, spec-DP, has the same or partly the same neural activation pattern as movement to spec-CP. In other words, does movement to spec-DP increase activation in Broca's area (and perhaps posterior temporal cortex)? Furthermore, does DP-internal movement map onto the cortical network in a fashion parallel to movement to IP and VP such that movement internal to the lexical core of NP activates the right hemisphere systems (parallel to the VP-domain)? And does movement that targets positions between NP and DP increase activation parallel to movement to the IP-domain (absence of activation or anterior temporal activation)?

As is evident, there is still much left for future research.

\section{Conclusion}

The idea of interface conditions applies not only to the structure-to-meaning mapping in syntax but also to the implementation of language in the brain. The Domain Hypothesis states that the interfacing between the derivational syntax and other cognitive systems is reflected in the brain as different activation patterns in a distributed network of computational sub-modules.

The Domain Hypothesis accounts for the results from the present fMRI experiment but also for the results from a variety of experiments and findings based and different theoretical assumptions: WM (Fiebach et al., 2005; Röder et al., 2002), syntactic chains (Ben-Shachar et al., 2003, 2004; Dogil et al., 2002), linearization of structure (Grewe et al., 2005), aphasia, 
movement, and thematic role assignment (Grodzinsky, 1990, 1995a, b, 2000), aphasia and syntactic structure (Friedmann, 2003; Friedmann \& Grodzinsky, 1997; Platzack, 2001b), and aphasia and feature movement (van der Meulen, 2004). Taken together, this large set of data cannot be accounted for in terms of canonicity, WM, or syntactic movement per se.

Interface conditions at the $\mathrm{CP}$-domain require that elements that are related to quantification and/or the level of discourse/pragmatics, such as topic and illocutionary force, be in CP. Movement to the CP-domain, such as wh-movement, significantly and consistently increases activation in Broca's area, whereas operations applying inside the VP-domain, where thematic information (thematic role assignment) is integrated, increase activation in the right frontal lobe. This is also compatible with results from research on aphasia (and other types of language impairment) and the activation patterns found in other fMRI studies. The present study shows that movement to IP, in fact, also has a cortical fingerprint, though not involving the frontal lobes but anterior temporal cortex.

What has hopefully become clear is that brain science and a formal approach to language may benefit from each other and thereby increase our knowledge and understanding of language and the brain, how they function and how they are structured.

\section{Acknowledgements}

The work reported here was supported by a grant from the Danish National Research Foundation to the Center for Functionally Integrative Neuroscience (CFIN). I would also like to acknowledge the staff at the MR Research Centre, Skejby Sygehus (Aarhus University Hospital), Denmark, where the experiments were performed.

\section{References}

Bastiaanse, R., Rispens, J., Ruigendijk, E., Rabadán, O. J., \& Thomson, C. (2002). Verbs: Some properties and their consequences for agrammatic Broca's aphasia. Journal of Neurolinguistics, 15, 239-264.

Ben-Shachar, M., Hendler, T., Kahn, I., Ben-Bashat, D., \& Grodzinsky, Y. (2003). The neural reality of syntactic transformations: Evidence from fMRI. Psychological Science, 14.5, 433-440.

Ben-Shachar, M., Palti, D., \& Grodzinsky, Y. (2004). Neural correlates of syntactic movement: Converging evidence from two fMRI experiments. NeuroImage, 21, 1320-1336.

Bishop, D. (1988). Language development after focal brain damage. In D. Bishop, \& K. Mogford (Eds.), (1988/ 1993), Language development in exceptional circumstances (pp. 203-219). Hove: Psychology Press Ltd.

Brownell, H. (2000). Right hemisphere contributions to understanding lexical connotation and metaphor. In Y. Grodzinsky, L. Shapiro, \& D. Swinney (Eds.), Language and the brain. Representation and processing (pp. 185-201). San Diego: Academic Press.

Burchert, F., Swoboda-Moll, M., \& de Bleser, R. (2005). The left periphery in agrammatic clausal representations: Evidence from German. Journal of Neurolinguistics, 18, 67-88.

Calvin, W. H., \& Ojemann, G. A. (1994). Conversations with Neil's brain. Reading, MA: Addison-Wesley.

Chomsky, N. (1995). The minimalist program. Cambridge, MA: MIT Press.

Chomsky, N. (2001). Derivation by phase. In M. Kenstowicz (Ed.), Ken Hale. A life in language (pp. 1-52). Cambridge, MA: MIT Press.

Chomsky, N. (2004). Beyond explanatory adequacy. In A. Belletti (Ed.), Structures and beyond. The cartography of syntactic structures, Vol. 3 (pp. 104-131). Oxford: Oxford University Press.

Chomsky, N. (2005). Three factors in language design. Linguistic Inquiry, 36.1, 1-22.

Chomsky, N. (in press). On phases. In R. Freidin, C.P. Otero, \& M.-L. Zubizarreta (Eds.), Foundational issues in linguistic theory. Cambridge, MA: MIT Press.

Christensen, K.R. (2005). Interfaces: Negation-syntax-brain. Ph.D. dissertation, Institute for Language, Literature, and Culture, Department of English, University of Aarhus. 
Cooke, A., Zurif, E. B., DeVita, C., Alsop, D., Koenig, P., Detre, J., et al. (2001). Neural basis for sentence comprehension: Grammatical and short-term memory components. Human Brain Mapping, 15.2, $80-94$.

Culicover, P. (2005). Linguistics, cognitive science, and all that jazz. The Linguistic Review, 22, 227-248.

Damasio, A. R. (1992). Aphasia. The New England Journal of Medicine, 326.8, 531-539.

Dapretto, M., \& Bookheimer, S. (1999). Form and content: Dissociating syntax and semantics in sentence comprehension. Neuron, 24, 427-432.

Deacon, T. (1997). The symbolic species. The co-evolution of language and the human brain. London: Penguin.

Diesing, M. (1997). Yiddish VP order and the typology of object movement in Germanic. Natural Language and Linguistic Theory, 15.2, 369-427.

Dogil, G., Ackermann, H., Grodd, W., Haider, H., Kamp, H., Mayer, J., et al. (2002). The speaking brain: A tutorial introduction to fMRI experiments in the production of speech, prosody and syntax. Journal of Neurolinguistics, 15, 59-90.

Donald, M. (1991). Origins of the modern mind. Three stages in the evolution of culture and cognition. Cambridge, MA: Harvard University Press.

Drai, D., \& Grodzinsky, Y. (2006). A new perspective on the variability debate: Quantitative neurosyntactic analyses of a large data set from Broca's Aphasia. Brain and Language, 76.2, 117-128.

Embick, D., Marantz, A., Miyashita, Y., O’Neil, W., \& Sakai, K. L. (2000). A syntactic specialization for Broca's area. PNAS, 97.11, 6150-6154.

Fiebach, C., Schlesewsky, M., Lohmann, G., von Cramon, D. Y., \& Friederici, A. D. (2005). Revisiting the role of Broca's area in sentence processing: Syntactic integration vs. syntactic working memory. Human Brain Mapping, 24, 79-91.

Friederici, A. D. (2002). Towards a neural basis of auditory sentence processing. Trends in Cognitive Sciences, 6.2, 78-84.

Friederici, A. D., Rüschemeyer, S.-A., Hahne, A., \& Fiebach, C. J. (2003). The role of left inferior frontal and superior temporal cortex in sentence comprehension: Localizing syntactic and semantic processes. Cerebral Cortex, 13, 170-177.

Friedmann, N. (2003). The fragile nature of the left periphery: CP deficits in agrammatic aphasia. In Proceedings of the 18th IATL conference.

Friedmann, N., \& Grodzinsky, Y. (1997). Tense and agreement in agrammatic production: Pruning the syntactic tree. Brain and Language, 56, 397-425.

Friston, K.J. (2003). Functional integration in the brain. In R. Frackowiak, K. Friston, C. Frith, R. Dolan, C. Price, J. Ashburner, W. Penny, \& S. Zeki (Eds.), Human brain function. (2nd ed.). London: Elsevier/Academic Press.

Fuster, J. M. (2003). Cortex and mind. Unifying cognition. Oxford: Oxford University Press.

Gibson, E. (1998). Linguistic complexity: Locality of syntactic dependencies. Cognition, 68, 1-76.

Grewe, T., Bornkessel, I., Zysset, S., Wiese, R., von Cramon, D. Y., \& Schlesewsky, M. (2005). Emergence of the unmarked: A new perspective on the language-specific function of Broca's area. Human Brain Mapping, 26, $178-190$.

Grodzinsky, Y. (1986). Language deficits and the theory of syntax. Brain and Language, 27, 135-159.

Grodzinsky, Y. (1990). Theoretical perspectives on language deficits. Cambridge, MA: MIT Press.

Grodzinsky, Y. (1995a). A restrictive theory of agrammatic comprehension. Brain and Language, 50, $27-51$.

Grodzinsky, Y. (1995b). Trace deletion, $\theta$-roles, and cognitive strategies. Brain and Language, 51, 469-497.

Grodzinsky, Y. (2000). The neurology of syntax: Language use without Broca's area. Behavioral and Brain Sciences, 23.1, 1-71.

Grodzinsky, Y. (2006). A blueprint for a brain map of syntax. In Y. Grodzinsky, \& K. Amunts (Eds.), Broca's region. New York: Oxford University Press.

Haegeman, L., \& Guéron, J. (1999). English grammar. Oxford: Blackwell.

Hagiwara, H. (1995). The breakdown of functional categories and the economy of derivation. Brain and Language, 50, 92-116.

Haider, H. (1997). Projective economy: On the minimal functional structure of the German clause. In W. Abraham, van Gelderen, \& Elly (Eds.), German: Syntactic problems-Problematic syntax (pp. 83-103). Tübingen: Max Niemeyer.

Haider, H. (2003). Scrambling: Nontriggered chain formation in OV languages. Journal of Germanic Linguistics, $15.3,203-267$.

Hinzen, W. (2006). Mind design and minimal syntax. Oxford: Oxford University Press. 
Humphries, C., Love, T., Swinney, D., \& Hickok, G. (2005). Response of anterior temporal cortex to syntactic and prosodic manipulations during sentence processing. Human Brain Mapping, 26, 128-138.

Ito, M. (2000). Neural control of cognition and language. In A. Marantz, Y. Miyashita, \& W. O’Neil (Eds.), Image, language, brain (pp. 149-162). Cambridge, MA: MIT Press.

Johnson, K. (1991). Object positions. Natural language and linguistic theory, 9, 577-636.

Just, M. A., Carpenter, P. A., Keller, T. A., Eddy, W. F., \& Thulborn, K. R. (1996). Brain activation modulated by sentence comprehension. Science, 274, 114-116.

Kimball, J. (1973). Seven principles of surface structure parsing in natural languages. Cognition, 2.1, 15-47.

Larson, R. K. (1988). On the double object construction. Linguistic Inquiry, 19, 335-391.

Lonzi, L., \& Luzzatti, C. (1993). Relevance of adverb distribution for the analysis of sentence representation in agrammatic patients. Brain and Language, 45.3, 306-317.

Maess, B., Koelsch, S., Gunter, T. C., \& Friederici, A. D. (2001). Musical syntax is processed in Broca's area: An MEG study. Nature Neuroscience, 4.5, 540-545.

Maldjian, J. A., Laurienti, P. J., \& Burdette, J. H. (2004). Precentral gyrus discrepancy in electronic version of the talairach atlas. Neuroimage, 21.1, 450-455.

Maldjian, J. A., Laurienti, P. J., Kraft, R. A., \& Burdette, J. H. (2003). An automated method for neuroanatomic and cytoarchitectonic atlas-based interogation of fMRI data sets. Neuroimage, 19.3, 1233-1239.

Marantz, A. (2005). Generative linguistics within the cognitive neuroscience of language. The Linguistic Review, $22,429-445$.

Müller, G. (2001). Order preservation, parallel movement, and the emergence of the unmarked. In G. Legendre, J. Grimshaw, \& S. Vikner (Eds.), Optimality-theoretic syntax (pp. 279-313). Cambridge MA: MIT Press.

Newman, S. D., Just, M. A., Keller, T. A., Roth, J., \& Carpenter, P. A. (2003). Differential effects of syntactic and semantic processing on the subregions of Broca's area. Cognitive Brain Research, 16, 297-307.

Osterhout, L., \& Nicol, J. (1999). On the distinctiveness, independence, and time course of the brain responses to syntactic and semantic anomalies. Language and Cognitive Processes, 14.3, 283-317.

Paradis, M. (1998). Language and communication in multilinguals. In B. Stemmer, \& H. A. Whitaker (Eds.), Handbook of neurolinguistics (pp. 417-430). New York: Academic Press.

Pinker, S. (1994). The language instinct. London: Penguin.

Platzack, C. (1998). Svenskans inre grammatik-det minimalistiska programmet. En introduktion till modern generativ grammatik. Lund: Studentlitteratur.

Platzack, C. (2001a). Multiple interfaces. In U. Nikanne, \& E. van der Zee (Eds.), Cognitive interfaces. Constraints on linking cognitive information (pp. 21-53). Oxford: Oxford University Press.

Platzack, C. (2001b). The vulnerable C-domain. Brain and Language, 77.3, 364-377.

Poeppel, D., \& Embick, D. (2004). Defining the relation between linguistics and neuroscience. In A. Cutler (Ed.), Twenty-first century psycholinguistics: Four cornerstones. Mahwah, NJ: Lawrence Erlbaum Associates, Inc (Ms. Published 2005).

Rizzi, L. (1997). The fine structure of the left periphery. In L. Haegeman (Ed.), Elements of grammar (pp. 281-337). Dordrecht: Kluwer Academic Publishers.

Röder, B., Stock, O., Neville, H., Bien, S., \& Rösler, F. (2002). Brain activation modulated by the comprehension of normal and pseudo-word sentences of different processing demands: A functional magnetic resonance imaging study. Neuroimage, 15, 1003-1014.

Saddy, D., \& Uriagereka, J. (2004). Measuring language. International Journal of Bifurcation and Chaos, 14.2, 383-404.

Schneiderman, E., \& Douglas, S. (1988). A linguistic deficit resulting from right hemisphere damage. Brain and Language, 34, 38-53.

Talairach, J., \& Tournoux, P. (1988). Co-planar stereotaxic atlas of the human brain. New York: Thieme Medical Publishers, Inc.

Tzourio-Mazoyer, N., Landeau, B., Papathanassiou, D., Crivello, F., Etard, O., Delcroix, N., et al. (2002). Automated anatomical labelling of activations in SPM using a macroscopic anatomical parcellation of the MNI MRI single-subject brain. Neuroimage, 15.1, 273-289.

Uriagereka, J. (1999). Multiple spell-out. In S. Epstein, \& N. Hornstein (Eds.), Working minimalism (pp. 251-282). Cambridge, MA: MIT Press.

van der Meulen, I. (2004). Syntactic movement and comprehension deficits in Broca's aphasia. Ph.D. dissertation. Utrecht: LOT.

Vikner, S. (1989). Object shift and double objects in Danish. Working Papers in Scandinavian Syntax, 44, 141-155. 
Vikner, S. (2001). Verb movement variation in germanic and optimality theory. Habilitationsschrift, Universität Tübingen.

Vikner, S. (2005). Object shift. In M. Everaert, \& H. van Riemsdijk (Eds.), The Blackwell companion to syntax. Oxford: Blackwell.

Vuust, P., Pallesen, K. J., Bailey, C., Van Zuijen, T. L., Gjedde, A., Roepstorff, A., et al. (2005). To musicians, the message is in the meter. Pre-attentive neuronal responses to incongruent rhythm are left-lateralized in musicians. Neuroimage, 24.2, 560-564.

Wartenburger, I., Heekeren, H. R., Burchert, F., Heinemann, S., de Bleser, R., \& Villringer, A. (2004). Neural correlates of syntactic transformations. Human Brain Mapping, 22, 72-81. 